\title{
Improved provincial emission inventory and speciation profiles of anthropogenic non-methane volatile organic compounds: a case study for Jiangsu, China
}

\author{
Yu Zhao ${ }^{1,2}$, Pan Mao ${ }^{1}$, Yaduan Zhou ${ }^{1}$, Yang Yang ${ }^{1}$, Jie Zhang ${ }^{2,3}$, Shekou Wang ${ }^{3}$, Yanping Dong ${ }^{4}$, Fangjian Xie ${ }^{5}$, \\ Yiyong $\mathrm{Yu}^{4}$, and Wenqing $\mathrm{Li}^{5}$ \\ ${ }^{1}$ State Key Laboratory of Pollution Control \& Resource Reuse and School of the Environment, Nanjing University, \\ 163 Xianlin Ave., Nanjing, Jiangsu 210023, China \\ ${ }^{2}$ Jiangsu Collaborative Innovation Center of Atmospheric Environment and Equipment Technology (CICAEET), \\ Nanjing University of Information Science \& Technology, Jiangsu 210044, China \\ ${ }^{3}$ Jiangsu Provincial Academy of Environmental Science, 176 North Jiangdong Rd., Nanjing, Jiangsu 210036, China \\ ${ }^{4}$ Nanjing Environmental Monitoring Central Station, 175 Huju Rd., Nanjing, Jiangsu 210013, China \\ ${ }^{5}$ Nanjing Academy of Environmental Protection Science, 175 Huju Rd., Nanjing, Jiangsu 210013, China
}

Correspondence to: Yu Zhao (yuzhao@nju.edu.cn)

Received: 13 December 2016 - Discussion started: 2 January 2017

Revised: 10 May 2017 - Accepted: 23 May 2017 - Published: 28 June 2017

\begin{abstract}
Non-methane volatile organic compounds (NMVOCs) are the key precursors of ozone $\left(\mathrm{O}_{3}\right)$ and secondary organic aerosol (SOA) formation. Accurate estimation of their emissions plays a crucial role in air quality simulation and policy making. We developed a high-resolution anthropogenic NMVOC emission inventory for Jiangsu in eastern China from 2005 to 2014, based on detailed information of individual local sources and field measurements of source profiles of the chemical industry. A total of 56 NMVOCs samples were collected in nine chemical plants and were then analyzed with a gas chromatography - mass spectrometry system (GC-MS). Source profiles of stack emissions from synthetic rubber, acetate fiber, polyether, vinyl acetate and ethylene production, and those of fugitive emissions from ethylene, butanol and octanol, propylene epoxide, polyethylene and glycol production were obtained. Various manufacturing technologies and raw materials led to discrepancies in source profiles between our domestic field tests and foreign results for synthetic rubber and ethylene production. The provincial NMVOC emissions were calculated to increase from $1774 \mathrm{Gg}$ in 2005 to $2507 \mathrm{Gg}$ in 2014 , and relatively large emission densities were found in cities along the Yangtze River with developed economies and industries. The estimates were larger than
\end{abstract}

those from most other available inventories, due mainly to the complete inclusion of emission sources and to the elevated activity levels from plant-by-plant investigation in this work. Industrial processes and solvent use were the largest contributing sectors, and their emissions were estimated to increase, respectively, from 461 to 958 and from 38 to $966 \mathrm{Gg}$. Alkanes, aromatics and oxygenated VOCs (OVOCs) were the most important species, accounting for 25.9-29.9, 20.8-23.2 and 18.2-21.0\% to annual total emissions, respectively. Quantified with a Monte Carlo simulation, the uncertainties of annual NMVOC emissions vary slightly through the years, and the result for 2014 was -41 to $+93 \%$, expressed as $95 \%$ confidence intervals (CI). Reduced uncertainty was achieved compared to previous national and regional inventories, attributed partly to the detailed classification of emission sources and to the use of information at plant level in this work. Discrepancies in emission estimation were explored for the chemical and refinery sectors with various data sources and methods. Compared with the Multi-resolution Emission Inventory for China (MEIC), the spatial distribution of emissions in this work were more influenced by the locations of large point sources, and smaller emissions were found in urban area for developed cities in southern Jiangsu. In addition, 
discrepancies were found between this work and MEIC in the speciation of NMVOC emissions under the atmospheric chemistry mechanisms CB05 and SAPRC99. The difference in species OLE1 resulted mainly from the updated source profile of building paint use and the differences in other species from the varied sector contributions to emissions in the two inventories. The Community Multi-scale Air Quality (CMAQ) model simulation was applied to evaluate the two inventories, and better performance (indicated by daily $1 \mathrm{~h}$ maximum $\mathrm{O}_{3}$ concentrations in Nanjing) were found for January, April and October 2012 when the provincial inventory was used.

\section{Introduction}

With strong $\mathrm{OH}$ and $\mathrm{HO}_{2}$ radical chemistry reactions, nonmethane volatile organic compounds (NMVOCs) are reported to play crucial roles in formation of secondary organic aerosols (SOAs) and serious photochemical pollution in China, particularly in developed cities and regions. For example, Huang et al. (2014) revealed that the contribution of SOA from NMVOC conversion reached $44-71 \%$ to ambient organic aerosols during a heavy haze period in winter, based on detailed analysis on chemistry composition and the source of airborne particles in four important cities (Beijing, Shanghai, Guangzhou and Xi' an) across the country. Due to intensive emissions of species with strong atmospheric oxidation capability (indicated by maximum incremental reactivity, MIR), ozone $\left(\mathrm{O}_{3}\right)$ formation was recognized as VOC limited in developed areas including the Jing-Jin-Ji (JJJ), Yangtze River Delta (YRD) and Pearl River Delta (PRD) regions (Geng et al., 2008; Shao et al., 2009; Zhang et al., 2008; Xing et al., 2011).

Given the impacts of NMVOCs on air quality, increasing attention has been paid to their sources and emission characteristics. Although natural sources dominate the emissions at global scale (Guenther et al., 1995; Muller, 1992; GEIA, http://eccad.sedoo.fr/eccad_extract_interface), the contribution from anthropogenic sources is elevated at smaller spatial scales, attributed to intensive human activities. In mainland China, emissions of natural and anthropogenic origin were estimated close to each other at 10-30 Tg, and anthropogenic emissions were dominated by solvent use and industrial processes (Tie et al., 2006; Klimont et al., 2002; Streets et al., 2003). Table $S 1$ in the Supplement briefly summarizes the estimations of China's national NMVOC emissions of anthropogenic origin from various studies. With different methods and data sources applied, NMVOC emissions in China were estimated to have doubled from 1990 to 2010, and the contributions of solvent use, non-combustion industrial processes and transportation were enhanced in recent years. Incorporating available information at national scale, Tsinghua University developed the Multi-resolution Emission Inventory for China (MEIC; http://www.meicmodel.org/) and calculated the national total emissions at $23.6 \mathrm{Tg}$ for 2010 . Among all the studies, the largest estimations were made in the regional emission inventory in Asia (REAS; Ohara et al., 2007; Kurokawa et al., 2013), reaching 28.0 Tg for 2008.

At local scale, emissions from anthropogenic sources could be much higher than natural sources. For example, anthropogenic NMVOC emissions were estimated to be 618 times those of natural origin in Beijing (Klinger et al., 2002; Wang et al., 2003; Klimont et al., 2002; Q. Zhang et al., 2009). With information on individual plants collected, emission inventories for regions with relatively heavy air pollution in China including JJJ, YRD and PRD have been developed, and differences in sector contribution were found. Solvent use and transportation were identified as the largest NMVOC sources in PRD (Zheng et al., 2009), while industrial processes were more important in YRD (Huang et al., 2011; Fu et al., 2013). Limitation existed in current regional inventories. First, information of local sources was still lacking. Although combustion sources (e.g., power plants) were gradually included in the regional emission inventory as point sources, the sources that contribute more to NMVOCs including refinery and chemical industry plants were less investigated at local scale, resulting possibly in a big bias in emission estimation. Second, with varied data sources and methods, large discrepancies might exist between studies in the amount and spatial patterns of emissions. Such discrepancies were rarely analyzed, and the uncertainties in emission estimation at local scale were seldom quantified. In particular, the performance of chemistry transport modeling based on various NMVOC inventories has not been sufficiently evaluated. Moreover, chemical speciation of NMVOC emissions needs further improvement. Domestic measurements have increasingly been conducted on chemical profiles of NMVOCs for typical source categories including solvent use (Yuan et al., 2010; Zheng et al., 2013), transportation (Tsai et al., 2012; Huang et al., 2015), residential stoves (Wang et al., 2009) and biomass burning (Kudo et al., 2014). The effects of those results on speciation of NMVOC emissions were not fully assessed, except in limited studies ( $\mathrm{Li}$ et al., 2014). In addition, the measurements on given sectors such as the chemical industry are still lacking, and the data from foreign countries had to be used.

Under the heavy haze pollution in eastern China (Andersson et al., 2015; Sun et al., 2015; Wang et al., 2015), series of measures have been conducted particularly on power and industrial boilers to control the emissions of primary particles and the precursors of secondary particles such as $\mathrm{SO}_{2}$ and $\mathrm{NO}_{x}$ (Zhao et al., 2014). Along with gradually reduced ambient $\mathrm{PM}$ levels in YRD, $\mathrm{O}_{3}$ pollution has become a bigger concern for air quality improvement, motivating better understanding and control of NMVOC emissions. In this work, we select Jiangsu, a typical province with intensive refinery and chemical industries in eastern China, to develop and evaluate the high-resolution emission inventory 
of anthropogenic NMVOCs. The geographic location and cities of the province are illustrated in Fig. S1 in the Supplement. Field measurements on the chemical composition of NMVOC emissions were conducted to obtain the source profiles of typical chemical industry processes. With detailed information of local emission sources collected and temporal changes tracked, a provincial emission inventory of speciated NMVOC was developed for a 10-year period (2005-2014), and the uncertainties of the emission estimation were quantified. Through a thorough comparison of results from varied methods and data sources, the discrepancies in emission estimation, source profiles, and spatial patterns were then evaluated. Finally, chemistry transport modeling was applied in southern Jiangsu to test the improvement of the provincial NMVOC inventory.

\section{Data and methods}

\subsection{Sampling and analysis of NMVOC species from chemical plants}

Chemical profiles of NMVOC emissions are still lacking for the chemical industry and oil exploitation and refinery in China due to a big variety of source categories. We select nine types of chemical engineering enterprises that are intensively distributed in Jiangsu to measure the chemistry composition of NMVOC emissions, as summarized in Table S2 in the Supplement. To our knowledge, no domestic measurement of NMVOC speciation has been conducted for those sources yet, and current work was expected to supplement the domestic source profiles for thr chemical industry. Based on the on-site investigation of main emission processes, the locations for stack and/or fugitive emission sampling were determined for each source type (see Table S2 for the details). Note that sampling could not be conducted for all processes in one enterprise due mainly to the limitation of pipeline layout. The SUMMA canister produced by University of California, Irvine, was employed to collect the air sample. The canister was made out of stainless steel as its inner wall, and the volume and vacuum pressure range of the canister were $2 \mathrm{~L}$ and $1.1 \times 10^{-4} \mathrm{kPa}$, respectively. For stack emission measurement, as shown in Fig. S2a in the Supplement, the canister was connected with a stainless steel probe, and a filter pipe filled with glass wool and anhydrous sodium sulfate was applied to remove the particles and water vapor in the air sample. Under flow control, the sampling time was roughly 10 min until the pressure in the canister became ambient. For fugitive emission measurement, the canister was placed $50 \mathrm{~m}$ downwind of the production device, and the sampling time was roughly $8 \mathrm{~min}$. Repeated sampling was conducted for each process to eliminate the bias, and a total of 56 samples were obtained, as shown in Table S2.

NMVOC samples were analyzed by a gas chromatography - mass spectrometry (GC-MS) system (GC6890/MS5973i,
Agilent Technologies, USA), as illustrated in Fig. S2b in the Supplement. Firstly, the sample was pumped into a cryogenic preconcentrator with a three-stage trapping system. In the first stage, the VOC species were adsorbed on glass beads at $-150{ }^{\circ} \mathrm{C}$ and desorbed at $10^{\circ} \mathrm{C}$. Vapor water was converted to solid water and was thus separated from the sample. In the second stage, the sample was trapped on Tenax at $-30^{\circ} \mathrm{C}$ and desorbed at $180^{\circ} \mathrm{C}$, and the target species were separated from $\mathrm{CO}_{2}$ and other compositions in the air. In the third stage, the sample was focused on a transfer line at $-160{ }^{\circ} \mathrm{C}$ and heated rapidly to $70{ }^{\circ} \mathrm{C}$, and the species were concentrated. The concentrated VOC was then injected into the gas chromatograph. The GC oven temperature was initially programmed at $-50^{\circ} \mathrm{C}$ and then increased to $180^{\circ} \mathrm{C}$ at $4^{\circ} \mathrm{C} \mathrm{min}{ }^{-1}$ and to $220^{\circ} \mathrm{C}$ at $15^{\circ} \mathrm{C} \mathrm{min}^{-1}$, holding $3 \mathrm{~min}$. The VOC compounds were separated on a DB-5MS capillary column $(60 \mathrm{~m} \times 0.25 \mathrm{~mm} \times 1.0 \mu \mathrm{m})$ and quantified using a quadrupole mass spectrometer. The mass spectrometer was operated in SCAN mode and scanned 20-42 and 35$270 \mathrm{amu}$ before and after $8.5 \mathrm{~min}$, respectively. The ionization method was electron impacting, and the source temperature was $230^{\circ} \mathrm{C}$. The PAMS (Photochemical Assessment Monitoring Station) standard mixture (Spectra Gases Inc., USA) and TO-15 standard mixture (Spectra Gases Inc., USA) were used to confirm the retention times of different compounds and to identify them based on retention time and mass spectrum. The target species were quantified by using a multipoint internal calibration method. To establish calibration curves, a certified gas mixture containing all the target compounds was dynamically diluted with pure nitrogen to five concentration gradients using mass flow controllers. Bromochloromethane, 1,2-difluorobenzene and chlorobenzened5 were chosen as internal standards in samples. The method detection limit was $0.5 \mathrm{ppb}$ for all species.

\subsection{Development of provincial emission inventory}

Different from national and regional inventories that relied mainly on energy and economic statistics, detailed information on individual emission sources was collected for Jiangsu, and interannual changes were tracked at plant level based on various databases. Those databases contained the multiple-year official environmental statistics (databases of emission sources routinely compiled by local environmental protection bureaus), Pollution Source Census (PSC, a thorough investigation of emission sources organized at national level), and on-site surveys of large emitters conducted by the local department of environmental supervision. The information included geographic location, types and amounts of raw materials, types and amounts of products, fuel quality and consumption, and combustion/manufacturing technology. For 2014, as an example, detailed information of 6023 plants was obtained, and the locations of those point sources are illustrated in Fig. S1. Incorporating the plantby-plant information and the energy and industrial statistics 
at provincial level, a four-level framework was established, covering all the anthropogenic NMVOC sources for Jiangsu, as summarized in Table 1. The framework included seven main categories: stationary fossil fuel combustion, industrial process, solvent use, transportation, oil distribution, biomass burning and others. Each main category was further subdivided into subcategories according to discrepancies in fuel consumption, product manufacturing or technology application. The emissions of the province for 2005-2014 were calculated using the following equation:

$E(n)=\sum_{i} \mathrm{AL}(i, n) \times \mathrm{EF}(i, n)$,

where $i$ and $n$ represent the source type and year, respectively; $E$ is the annual emissions; AL is the activity level data; and $\mathrm{EF}$ is the emission factor (i.e., emissions per unit of AL). As summarized in Table 2, emission factors were collected from extensive literatures and determined as follows with descending priorities: (1) results from domestic measurements; (2) emission limits of local laws and regulations; (3) values from expert judgment specific for China; and (4) emission factors from AP-42 database (USEPA, 2002) and the EMEP/EEA guidebook (EEA, 2013) when domestic information was lacking. Details will be discussed by sector in Sect. 2.3.

The total NMVOC emissions for given source type were then broken down into individual species using Eq. (2):

$E(i, k)=E(i) \times X(i, k)$,

where $E$ is the emissions; $i$ and $k$ represent the source type and individual NMVOCs species, respectively; $X$ is chemical profile of NMVOCs (\%). To reduce the uncertainty of source profile from individual measurement, Li et al. (2014) developed the "composite profiles" for sources where multiple candidate profiles were available, by revising the OVOC fraction and averaging the fractions in different profiles for each species. As a more detailed source classification was applied in this work, some sources (e.g., biomass open burning, automobile production and repairing, and wood decoration and wooden furniture paint) were not covered by $\mathrm{Li}$ et al. (2014), and thus the results from SPECIATE (USEPA, 2014) were applied instead. We named the combination of $\mathrm{Li}$ et al. (2014) and SPECIATE as a source profile "before updating" hereinafter. While Li et al. (2014) included the source profiles published before 2011, a series of local measurements was conducted since then. In this work, therefore, "composite profiles" were updated following the method by $\mathrm{Li}$ et al. (2014). The most recent domestic results and the measurements conducted in this work were incorporated, as summarized by source types in Sect. 2.3.

To evaluate the atmospheric oxidation capability from NMVOC emissions, ozone formation potentials (OFPs) were calculated by multiplying the speciated NMVOC emissions and corresponding MIR values (Carter, 1994). To meet the requirement of atmospheric modeling, NMVOC emissions were assigned to chemical mechanism (CB05 and SAPRC99) species by multiplying the emissions of individual species and mechanism-specific conversion factors using the following equation:

$E(i, m)=\frac{E(i, k)}{M(k)} \times C(k, m)$,

where $E$ is the emissions; $M$ is the mole weight; $C$ is the conversion factor; and $i, k$ and $m$ represent the source type, individual species and the chemical mechanism species.

The uncertainty of estimated provincial emissions was quantified using a Monte Carlo framework (Zhao et al., 2011) for each year. Probability distribution functions (PDFs) were determined for all the parameters involved in the emission calculation, and 10000 simulations were performed to estimate the uncertainties of emissions. The parameters that were most significant in determination of the uncertainties were identified by source type according to the rank of their contributions to variance. The detailed information of PDF assumption will be provided by sector in Sect. 2.3.

\subsection{Data sources of emission inventory development by category}

\subsubsection{Combustion sources (fossil fuel combustion and biomass burning)}

For power sector and heating/industrial boilers, activity data were compiled at plant level based on the information obtained from environmental statistics, PSC and on-site surveys. The annual amount of residential fossil fuel combustion for 2005-2014 and that of biofuel use for residential stoves until 2008 were directly taken from Chinese official energy statistics (NBS, 2015a). As the data were unavailable for subsequent years for biofuel, the activity level was calculated as a product of grain production, waste-to-grain ratio and the ratio of residual material burned in stoves according to the government plan of biomass utilization (PGJP, 2009). The biomass combusted in open fields was calculated as a product of grain production, waste-to-grain ratio and the percentage of residual material burned in the field (Wang and Zhang, 2008; PGJP, 2009), as described in Zhao et al. (2011, 2013). Following the rules of IPCC (2006), the uncertainties of activity levels were determined according to the reliability of energy and economy statistics. As shown in Table S3 in the Supplement, normal distributions were assumed with the coefficient of variation $(\mathrm{CV}$, the standard deviation divided by the mean) determined at 5, 10,20 and $30 \%$ for power, industrial, residential fossil fuel and biomass combustion sources, respectively.

As summarized in Table 2, emission factors for power plants and industrial boilers were taken mainly from Bo et al. (2008). Given the similar designs of boilers between China and developed countries (Wei et al., 2008), AP-42 
Table 1. Categories of anthropogenic NMVOC emission sources.

\begin{tabular}{|c|c|c|c|}
\hline Sector & Subsector & Product/fuel/solvent use & Product/technology \\
\hline \multirow{3}{*}{$\begin{array}{l}\text { Fossil fuel } \\
\text { stationary } \\
\text { combustion }\end{array}$} & Power plant & Coal/oil/natural gas/waste/biofuel & NA \\
\hline & $\begin{array}{l}\text { Heating and industrial } \\
\text { boiler }\end{array}$ & Coal/coke/oil/natural gas & NA \\
\hline & Residential & Coal/oil/liquified petroleum gas (LPG)/natural gas & NA \\
\hline \multirow{3}{*}{$\begin{array}{l}\text { Biomass } \\
\text { burning }\end{array}$} & Boiler & NA & NA \\
\hline & Stove burning & Crop straw/wood & NA \\
\hline & Open burning & Crop straw & Rice/corn/wheat/other \\
\hline \multirow{16}{*}{$\begin{array}{l}\text { Industrial } \\
\text { process }\end{array}$} & Iron and steel & Coking & Mechanical/indigenous \\
\hline & & Sinter/pellet/crude steel & NA \\
\hline & Non-metallic mineral & Glass & Flat glass/glass fiber/glass work \\
\hline & & Cement clinker/lime/brick and tile/ceramic & NA \\
\hline & $\begin{array}{l}\text { Oil exploitation and } \\
\text { refinery }\end{array}$ & Crude oil exploit/crude oil refinery & NA \\
\hline & Chemical industry & $\begin{array}{l}\text { Chemical raw materials: ethylene/benzene/methanol/ } \\
\text { acetic acid/synthesis ammonia/phthalic acid/ethylene } \\
\text { oxide/vinyl acetate/styrene/glycol/octanol/butanol }\end{array}$ & NA \\
\hline & & Synthetic chemical industry: synthetic resin & $\begin{array}{l}\text { Polyethylene/polypropylene/ } \\
\text { Polystyrene/polyvinyl chloride }\end{array}$ \\
\hline & & Synthetic chemical industry: synthetic fiber & $\begin{array}{l}\text { Viscose/cellulose acetate } \\
\text { fiber/nylon fiber }\end{array}$ \\
\hline & & Synthetic chemical industry: synthetic rubber & NA \\
\hline & & $\begin{array}{l}\text { Fine chemical industry: pharmaceutical/chemical } \\
\text { pesticide/paint/printing ink/adhesive/dye }\end{array}$ & NA \\
\hline & Food and wine & Fermentation alcohol/spirit/beer & NA \\
\hline & & Bread/cake/biscuit & NA \\
\hline & & Vegetable oil extraction & NA \\
\hline & $\begin{array}{l}\text { Plastic and rubber } \\
\text { product }\end{array}$ & Foam plastic/plastic products/tire/other rubber product & NA \\
\hline & Textile industry & Silk/cloth/woolen yarn & NA \\
\hline & Carbon black & & NA \\
\hline \multirow[t]{9}{*}{ Solvent use } & Paint use & Interior/exterior building coating & Water based/solvent based \\
\hline & & Automobile production/repairing & NA \\
\hline & & Wood decoration/wooden furniture paint & NA \\
\hline & & Anticorrosive paint & NA \\
\hline & & Other paint & NA \\
\hline & Printing & New-type/traditional ink & NA \\
\hline & Dyeing & & NA \\
\hline & Adhesive use & Shoe making/timber production/other & NA \\
\hline & Other solvent use & $\begin{array}{l}\text { Agriculture pesticide/Dry cleaning/household solvent } \\
\text { use/solvent degreasing }\end{array}$ & NA \\
\hline \multirow[t]{3}{*}{ Transportation } & On-road & Automobile & $\begin{array}{l}\text { Load (light/heavy) fuel } \\
\text { (gasoline/diesel) }\end{array}$ \\
\hline & & Motorcycle & Gasoline \\
\hline & Off-road & $\begin{array}{l}\text { Train/inland ship/construction machine/tractor/ } \\
\text { agriculture truck/agriculture machine }\end{array}$ & NA \\
\hline Oil distribution & $\begin{array}{l}\text { Crude oil/ } \\
\text { gasoline/diesel }\end{array}$ & Storage/transport/load and unload/gas station & NA \\
\hline Others & & $\begin{array}{l}\text { Garbage disposal } \\
\text { Cooking fume }\end{array}$ & $\begin{array}{l}\text { Burning/landfill/compost } \\
\text { NA }\end{array}$ \\
\hline
\end{tabular}


Table 2. NMVOC emission factors for combustion sources, industrial processes and solvent use. Unless specifically noted, the units are $\mathrm{g} \mathrm{kg}^{-1}$ (fuel), $\mathrm{g} \mathrm{kg}^{-1}$ (products) and $\mathrm{g} \mathrm{kg}^{-1}$ (solvents), respectively.

\begin{tabular}{|c|c|c|c|c|}
\hline Source & \multicolumn{2}{|c|}{ Fuel/product/solvent use } & EFs in this study & EFs in the references \\
\hline \multicolumn{5}{|l|}{ Combustion } \\
\hline \multirow[t]{12}{*}{ Fossil fuel } & \multirow[t]{3}{*}{ Power plant } & Coal & 0.15 & $\begin{array}{l}0.15^{\mathrm{a}} ; \quad 0.81^{\mathrm{b}} ; \quad 0.02^{\mathrm{c}} ; \quad 0.03- \\
0.03^{\mathrm{d}} ; 0.02^{\mathrm{e}}\end{array}$ \\
\hline & & Fuel oil & 0.09 & $3.88^{\mathrm{b}} ; 0.04^{\mathrm{c}} ; 0.12^{\mathrm{d}} ; 0.09-0.14^{\mathrm{e}}$ \\
\hline & & Natural gas $\left(\mathrm{g} \mathrm{m}^{-3}\right)$ & 0.083 & $0.12^{\mathrm{c}} ; 0.08-0.10^{\mathrm{d}} ; 0.08-0.10^{\mathrm{e}}$ \\
\hline & \multirow{4}{*}{$\begin{array}{l}\text { Heating and } \\
\text { industrial boiler }\end{array}$} & Coal & 0.18 & $0.18^{\mathrm{a}} ; 3.95^{\mathrm{b}} ; 0.04^{\mathrm{c}}$ \\
\hline & & & & $0.03-0.03^{\mathrm{d}} ; 0.02^{\mathrm{e}}$ \\
\hline & & Fuel oil & 0.12 & $3.88^{\mathrm{b}} ; 0.12^{\mathrm{c}} ; 0.12^{\mathrm{d}} ; 0.09-0.14^{\mathrm{e}}$ \\
\hline & & Natural gas $\left(\mathrm{g} \mathrm{m}^{-3}\right)$ & 0.094 & $0.1^{\mathrm{c}} ; 0.08-0.10^{\mathrm{d}} ; 0.08-0.10^{\mathrm{e}}$ \\
\hline & \multirow[t]{5}{*}{ Residential } & Coal & 4.5 & $\begin{array}{l}0.6^{\mathrm{a}} ; 3.08^{\mathrm{b}} ; 6.48,4.98^{\mathrm{g}} ; 4.5^{\mathrm{c}} ; \\
6.41^{\mathrm{d}}\end{array}$ \\
\hline & & Fuel oil & 0.35 & $0.35^{\mathrm{c}}$ \\
\hline & & LPG & 5.29 & $\begin{array}{l}0.17^{\mathrm{a}, \mathrm{b}} ; 3.28^{\mathrm{g}} ; 5.29^{\mathrm{c}} \\
66\left(\mathrm{~g} \mathrm{~m}^{-3}\right)^{\mathrm{e}}\end{array}$ \\
\hline & & Natural gas $\left(\mathrm{g} \mathrm{m}^{-3}\right)$ & 0.15 & $0.13^{\mathrm{c}} ; 0.15^{\mathrm{c}} ; 0.14^{\mathrm{d}} ; 0.18^{\mathrm{e}}$ \\
\hline & & Coal gas & 0.00044 & $0.00044^{\mathrm{a}}$ \\
\hline \multirow[t]{7}{*}{ Biomass burning } & \multirow{3}{*}{$\begin{array}{l}\text { Boiler } \\
\text { Stove burning }\end{array}$} & Biomass & 1.1 & $0.0015^{\mathrm{e}} ; 1.1^{\mathrm{f}}$ \\
\hline & & Wood & 3.23 & $1.09-4.94^{\mathrm{g}} ; 3.23^{\mathrm{c}} ; 5.3^{\mathrm{e}}$ \\
\hline & & Crop straw & 13.77 & $\begin{array}{l}1.7-3.0 \quad\left(\text { corn } \text { straw }^{\mathrm{g}}, 8.89\right. \\
(\text { wheat straw })^{\mathrm{g}} ; 13.77^{\mathrm{c}} ; 8.55^{\mathrm{d}} ; \\
5.3^{\mathrm{e}}\end{array}$ \\
\hline & \multirow[t]{4}{*}{ Open burning } & Rice straw & 7.48 & $7.48^{\mathrm{h}}$ \\
\hline & & Wheat straw & 7.48 & $7.48^{\mathrm{h}}$ \\
\hline & & Corn straw & 10.4 & $10.4^{\mathrm{h}}$ \\
\hline & & Other straws & 8.94 & $\begin{array}{l}\text { Average of straw open burning } \\
\text { above }\end{array}$ \\
\hline \multicolumn{5}{|l|}{ Industrial process } \\
\hline Iron and steel & \multicolumn{2}{|c|}{ Coking/sintering/steel } & $3.96 / 0.25 / 0.06$ & $3.4^{\mathrm{c}} ; 3.96^{\mathrm{f}} / 0.25^{\mathrm{f}} / 0.06^{\mathrm{f}}$ \\
\hline \multirow[t]{2}{*}{ Non-metallic mineral } & \multirow{2}{*}{\multicolumn{2}{|c|}{$\begin{array}{l}\text { Flat glass/glass fiber/glass work } \\
\text { Cement clinker/lime/brick and tile/ceramic }\end{array}$}} & $4.4 / 3.15 / 4.4$ & $4.4^{\mathrm{c}, \mathrm{f}} ; 3.5^{\mathrm{e}} / 3.15^{\mathrm{a}, \mathrm{i}} / 4.4^{\mathrm{f}}$ \\
\hline & & & $0.33 / 0.177 / 0.13 / 29.22$ & $\begin{array}{l}0.12^{\mathrm{c}} ; 0.018^{\mathrm{d}} ; 0.33^{\mathrm{f}} / 0.177^{\mathrm{f}} / \\
0.01^{\mathrm{i}} ; 0.2^{\mathrm{c}} ; 0.033^{\mathrm{a}} ; 0.13^{\mathrm{f}} / 29^{\mathrm{c}} \\
29.215^{\mathrm{a}} ; 29.22^{\mathrm{c}}\end{array}$ \\
\hline \multicolumn{3}{|l|}{ Oil exploitation/refinery } & $1.42 / 1.82$ & $1.42^{\mathrm{f}} / 1.82^{\mathrm{f}} ; 1.05^{\mathrm{d}} ; 3.54^{\mathrm{e}}$ \\
\hline \multirow[t]{10}{*}{ Chemical industry } & \multirow{2}{*}{\multicolumn{2}{|c|}{$\begin{array}{l}\text { Ethylene/benzene/methanol } \\
\text { Polyethylene/polypropylene }\end{array}$}} & $0.097 / 0.1 / 5.95$ & $0.097^{\mathrm{f}} ; 0.6^{\mathrm{d}} / 0.1^{\mathrm{f}} ; 0.25^{\mathrm{j}} / 5.95^{\mathrm{f}}$ \\
\hline & & & $10 / 8$ & $\begin{array}{l}10^{\mathrm{f}, \mathrm{j}} ; 0.33^{\mathrm{e}} ; 3.4^{\mathrm{d}} / 8^{\mathrm{f}, \mathrm{j}} ; 0.35^{\mathrm{e}} ; \\
4^{\mathrm{d}} ;\end{array}$ \\
\hline & \multicolumn{2}{|c|}{ Polystyrene/polyvinyl chloride } & $5.4 / 3$ & $\begin{array}{l}5.4^{\mathrm{f}} ; \quad 0.21-3.34^{\mathrm{e}} ; \quad 0.12^{\mathrm{d}} / 3^{\mathrm{f}, \mathrm{j}} \\
0.33-8.5^{\mathrm{e}} ; 0.096^{\mathrm{d}}\end{array}$ \\
\hline & \multicolumn{2}{|c|}{ Acetic acid/ammonia/phthalic anhydride } & $1.814 / 4.72 / 21$ & $\begin{array}{l}1.81^{\mathrm{i}} / 4.72^{\mathrm{f}, \mathrm{e}} / 1.1-6.3^{\mathrm{e}} ; 1.3-6^{\mathrm{d}} ; \\
21^{\mathrm{j}}\end{array}$ \\
\hline & \multicolumn{2}{|c|}{ Ethylene oxide/vinyl acetate/styrene } & $3 / 4.705 / 0.223$ & $\begin{array}{l}3^{\mathrm{f}} ; 0.98^{\mathrm{e}} ; 2^{\mathrm{d}} ; 4^{\mathrm{j}} / 4.705^{\mathrm{i}} / 0.223^{\mathrm{f}} ; \\
1^{\mathrm{d}} ; 3.1^{\mathrm{j}}\end{array}$ \\
\hline & \multicolumn{2}{|c|}{ Viscose fiber/cellulose acetate fiber/nylon fiber } & $14.5 / 73.4 / 3.3$ & $14.5^{\mathrm{c}, \mathrm{f}} / 73.4^{\mathrm{f}} ; 112^{\mathrm{e}} / 2.13-3.93$ \\
\hline & \multicolumn{2}{|c|}{ Polyester fiber/acrylic fibers polypropylene fiber } & $0.7 / 40 / 37.1$ & $0.7^{\mathrm{f}} ; 0.6^{\mathrm{e}} / 3.75-40^{\mathrm{e}} / 37.1^{\mathrm{c}}$ \\
\hline & \multicolumn{2}{|c|}{ Synthetic rubber } & 7.17 & $7.17^{\mathrm{f}, \mathrm{e}} ; 3.8-8.6^{\mathrm{e}} ; 0.27-9^{\mathrm{d}}$ \\
\hline & \multicolumn{2}{|c|}{ Pharmaceutical/chemical pesticide } & $430 / 20$ & $430^{\mathrm{f}, \mathrm{e}} ; 300^{\mathrm{d}} / 20^{\mathrm{k}}$ \\
\hline & \multicolumn{2}{|c|}{ Paint/printing ink/adhesive/dye/pigment } & $15 / 50 / 30 / 81.4 / 10$ & $\begin{array}{l}15^{\mathrm{f}, \mathrm{e}} ; 11^{\mathrm{d}} / 50^{\mathrm{f}} ; 60^{\mathrm{e}} / 30^{\mathrm{c}} \\
20^{\mathrm{f}} / 81.4^{\mathrm{f}} / 10^{\mathrm{i}}\end{array}$ \\
\hline
\end{tabular}


Table 2. Continued.

\begin{tabular}{|c|c|c|c|}
\hline Source & Fuel/product/solvent use & EFs in this study & EFs in the references \\
\hline \multicolumn{4}{|l|}{ Industrial process } \\
\hline \multirow[t]{2}{*}{ Plastic and rubber } & Foamed plastic/plastic products & $120 / 3.2$ & $770^{\mathrm{c}} ; 120^{\mathrm{d}} / 3.2^{\mathrm{f}, \mathrm{j}}$ \\
\hline & Tire/other rubber products & $0.91\left(\mathrm{~kg} \mathrm{tire}^{-1}\right) / 12.5$ & $\begin{array}{l}0.285\left(\mathrm{~kg} \mathrm{tire}^{-1}\right)^{\mathrm{m}} ; 0.285\left(\mathrm{~kg} \mathrm{tire}^{-1}\right)^{1} ; \\
0.91\left(\mathrm{~kg} \mathrm{tire}^{-1}\right)^{\mathrm{f}} ; 10^{\mathrm{d}} ; 0.659^{\mathrm{i}} / 12.5^{\mathrm{c}}\end{array}$ \\
\hline \multirow[t]{4}{*}{ Food and wine } & Fermentation alcohol/white spirit & $60 / 25$ & $\begin{array}{l}218.25^{\mathrm{f}} ; 60^{\mathrm{d}} / 25.35^{1} ; 25^{\mathrm{c}, \mathrm{f}} ; 150 \\
\left(\mathrm{~g} \mathrm{~L}^{-1}\right)^{\mathrm{d}} ; 33.105\left(\mathrm{~g} \mathrm{~L}^{-1}\right)^{\mathrm{i}}\end{array}$ \\
\hline & Beer/grape wine & $0.25 / 0.5$ & $\begin{array}{l}0.44^{1} ; 0.4^{\mathrm{c}} ; 0.43\left(\mathrm{~g} \mathrm{~L}^{-1}\right)^{\mathrm{a}} ; 0.25^{\mathrm{f}} ; 0.35 \\
\left(\mathrm{~g} \mathrm{~L}^{-1}\right)^{\mathrm{d}} / 0.81^{1} ; 0.5^{\mathrm{c}, \mathrm{f}} ; 0.8\left(\mathrm{gL}^{-1}\right)^{\mathrm{d}} ; \\
0.38\left(\mathrm{~g} \mathrm{~L}^{-1}\right)^{\mathrm{e}}\end{array}$ \\
\hline & Cake and biscuit & 1 & $1^{1, \mathrm{c}, \mathrm{d}, \mathrm{f}}$ \\
\hline & Vegetable oil extraction & 3.7 & $\begin{array}{l}3.45-10.35^{1} ; 5.5^{\mathrm{c}} ; 3.45^{\mathrm{a}} ; 1.57 \\
\left(\mathrm{~g} \mathrm{~L}^{-1}\right)^{\mathrm{d}} ; 4^{\mathrm{i}}\end{array}$ \\
\hline Textile industry & Silk/cloth/woolen & $10 / 10 / 10$ & $10^{\mathrm{b}} / 10^{\mathrm{b}} / 10^{\mathrm{b}}$ \\
\hline Carbon black & NA & 64.7 & $90^{\mathrm{m}} ; 73.2^{1} ; 64.7^{\mathrm{c}} ; 52^{\mathrm{f}} ; 0.7^{\mathrm{d}} ; 53.57^{\mathrm{e}} ;$ \\
\hline \multicolumn{4}{|l|}{ Solvent use } \\
\hline Printing & New-type/traditional ink & $100 / 750$ & $100^{\mathrm{f}} ; 150^{\mathrm{c}} / 750^{\mathrm{f}} ; 650^{\mathrm{c}}, 500$ \\
\hline Dyeing & - & 81.4 & $81.4^{\mathrm{e}, \mathrm{f}}$ \\
\hline \multirow[t]{6}{*}{ Paint use } & Interior wall painting & $250 ; 120^{\circ}$ & $250^{\mathrm{c}} / 120^{\mathrm{n}}$ \\
\hline & Exterior wall painting: aqueous/solvent & $120 / 580$ & $120^{\mathrm{f}} / 360^{\mathrm{f}} ; 585^{\mathrm{c}} ; 580^{\mathrm{n}} ; 230^{\mathrm{d}}$ \\
\hline & Vehicle manufacture/refinishing & $470 / 720$ & $460^{\mathrm{n}} ; 470^{\mathrm{c}} ; 475^{1} / 720^{\mathrm{c}, \mathrm{d}} ; 850^{1}$ \\
\hline & Furniture: aqueous/solvent based & $250 / 670$ & $250^{\mathrm{c}} / 640^{\mathrm{f}} ; 637^{\mathrm{n}} ; 550-750^{\mathrm{c}}$ \\
\hline & Anticorrosive paint use & 442 & $442^{\mathrm{c}}$ \\
\hline & Other paint use & 240 & $240^{\mathrm{c}}$ \\
\hline \multirow[t]{3}{*}{ Adhesive use } & Shoe making & 670 & $664^{\mathrm{n}} ; 670^{\mathrm{c}}$ \\
\hline & Timber production & 90 & $88^{\mathrm{n}} ; 90^{\mathrm{c}}$ \\
\hline & Other adhesive use & 89 & $89^{\mathrm{c}} ; 85^{1}$ \\
\hline \multirow[t]{4}{*}{ Other solvent } & Agriculture pesticide & 470 & $368-482^{\mathrm{c}} ; 356-576^{\mathrm{f}}$ \\
\hline & Dry cleaning & $0.16^{\mathrm{p}}$ & $0.8^{\mathrm{e}}$ \\
\hline & Household solvent use & 0.08 & $0.08^{\mathrm{f}} ; 3.7^{\mathrm{d}} ; 4.2^{\mathrm{e}} ; 0.1^{\mathrm{a}}$ \\
\hline & Degreasing & 0.044 & $0.044^{\mathrm{a}, \mathrm{f}}$ \\
\hline
\end{tabular}

${ }^{\mathrm{a}}$ Bo et al. (2008). ${ }^{\mathrm{b}}$ Tang and Chen (2002). ${ }^{\mathrm{c}}$ Wei et al. (2008), Wei (2009) and Wang et al. (2009). ${ }^{\mathrm{d}}$ EEA (2013). ${ }^{\mathrm{e}}$ USEPA (2002). ${ }^{\mathrm{f}}$ MEP (2014). ${ }^{\mathrm{g}}$ Zhang et al. (2000). ${ }^{\mathrm{h}}$ Li et al. (2007). ${ }^{\mathrm{i}}$ ROC EPA (2009). ${ }^{\mathrm{j}}$ Fan et al. (2012). ${ }^{\mathrm{k}}$ Xia et al. (2014). ${ }^{1}$ Wang (2006). ${ }^{\mathrm{m}}$ Klimont et al. (2002). ${ }^{\mathrm{n}}$ Fu et al. (2013). ${ }^{\mathrm{o}}$ 250 and 120 g kg ${ }^{-1}$ for 2005-2007 and 2008-2014, respectively. ${ }^{\mathrm{P}}$ adjusted by per capital income.

database were also applied when domestic results were lacking. For residential combustion of fossil fuel, emission factors from domestic tests (Zhang et al., 2000; Wang et al., 2009) were used. Wang et al. (2009) measured the NMVOC emission characteristics of multiple stove-biofuel combinations in China, and the obtained emission factors were used in this work. For biomass open burning, the local test results by Li et al. (2007) were applied. Chemical profiles were updated by incorporating domestic measurements for residential fossil fuel and biofuel burning (Tsai et al., 2003; Liu et al., 2008; Wang et al., 2009; H. Wang et al., 2014a) and biomass open burning (Zhang et al., 2013; Kudo et al., 2014). As measurement results were insufficient for data fitting, un- certainty of the emission factor was evaluated depending on expert judgment for combustion sources (Streets et al., 2003; Wei et al., 2011). The PDF of the emission factor was given according to reliability of data sources and/or the robustness of calculation methods (Wei et al., 2011; also the case for other sources as indicated below). As summarized in Table S4 in the Supplement, lognormal distributions were assumed with CVs set at 150 and $200 \%$ for fossil fuel and biomass burning, respectively. 


\subsubsection{Industrial processes}

Similar to power and industrial combustion, the activity levels of industrial processes were mainly collected at plant level by source category. However, small discrepancies existed between the compiled data at plant level and the officially reported production from economic statistics at provincial level (NBS, 2015b). In 2012, for example, the steel production aggregated from individual plants accounted for $98 \%$ of the provincial total production (Zhou et al., 2017). In this work, we treated the individual plants as point sources, and the fraction that was not covered in plant-by-plant databases as area sources. We assumed the PDFs of industrial production to have a normal distribution, with CVs at 10 and $20 \%$ for point and area sources, respectively.

Attributed to a wide variety of manufacturing procedures and complicated VOC exhaust processes, there were few local tests available on emission factors prior; thus, the values from expert judgment (i.e., data from routine investigations reported by the factory officials to local environmental protection bureaus) and data from AP-42 and EMEP/EEA had to be applied, as summarized in Table 2. Source profiles of chemical production including rubber, polyether and polyethylene were obtained from our measurements described in Sect. 2.1. Chemical profiles from the most recent domestic measurements were taken for other sources including iron and steel (Shi et al., 2015; He et al., 2005; Jia et al., 2009; Tsai et al., 2008; Li et al., 2014), paint and printing ink production (Zheng et al., 2013) and refineries (Liu et al., 2008; Wei et al., 2014). For sources without sufficient local tests (e.g., food and wine production), results from foreign studies were applied including the SPECIATE database by USEPA (2014) and Theloke and Friedirch (2007). Given the potential large uncertainties, a lognormal distribution with the CV set at $500 \%$ (i.e., a long-tailed PDF) was assumed for emission factors for most industrial processes.

\subsubsection{Solvent use}

Although solvent-use enterprises were contained in the plantby-plant surveys, many of them failed to report the actual solvent usage. Underestimation of activity levels and thereby emissions could be expected if the information at plant level was relied on. As the solvent usage was not directly reported at city level, we followed Wei (2009) to estimate the activity levels for the sector. The total solvent consumption at national level was first obtained according to the solvent production and imports and exports statistics (CNLIC, 2015; GAC, 2015). The provincial level was then calculated based on the intensities of activities that consume solvents (e.g., building construction and vehicle production). Finally, the provincial data were allocated to point sources according to production of individual plants and area sources according to distribution of industrial gross domestic product (GDP). Normal and lognormal distributions with CVs set at 20 and
$80 \%$ were applied for the activity levels of point and area sources of solvent use, respectively, indicating much larger uncertainty for the latter (Wei, 2009).

The VOC contents of solvents were limited by national laws and regulations, as summarized by Wei et al. (2008). The updating of regulations and their impacts on interannual changes in NMVOC emission factors were considered from 2005 to 2014, such as GB18583-2003 and GB18583-2008 for indoor painting. Bias needs to be admitted here, and possible underestimation of emissions would be expected for the sector, as the regulations were not strictly enforced particularly for small solvent-use enterprises and construction sites (area sources). Data from AP-42, EMEP/EEA and other literature (Bo et al., 2008; Fu et al., 2013) were applied when local information was missing, as provided in Table 2. The domestic tests on chemical species (Yuan et al., 2010; Zheng et al., 2013; H. Wang et al., 2014b) were included to update the source profiles of the sector. For uncertainty of the emission factors, a uniform distribution was tentatively applied (Table S4).

\subsubsection{Transportation}

The activity data of off-road transportation for 2005-2010 was taken from Zhao et al. (2013), and the data for other years were scaled according to the changes in passenger and freight traffic by rail and shipping, and those in numbers of agricultural and construction equipments (NBS, 2015c). For on-road transportation, activity data (total kilometers traveled) by vehicle type and control stage were calculated as the product of vehicle population and annual average kilometers traveled (VKT). The fleet composition by control stage was obtained from the survey by local government (internal data; Zhao et al., 2015), and VKTs by vehicle type were determined according to previous studies (Cai and Xie, 2007; Wang et al., 2008) and the guidebook of emission inventory development for Chinese cities (He, 2015). While the CV of transportation activities at national level was estimated at $16 \%$ (Zhao et al., 2011), larger uncertainties were assumed at provincial level (Wei, 2009). We followed Wei (2009) and assumed normal and lognormal distribution with CVs at 30 and $50 \%$ for on-road and off-road transportation, respectively.

For emission factors of off-road transportation, the data from EMEP/EEA and expert judgment (Wei et al., 2008; Q. Zhang et al., 2009) were adopted, attributed to a lack of domestic tests or relevant standards/regulations. Following He (2015), the emission factors for on-road vehicles were calculated and adjusted according to local conditions using Eq. (4):

$\mathrm{EF}=\mathrm{BEF} \times \varphi \times \gamma \times \lambda \times \theta$

where $\mathrm{BEF}$ is the base emission factor, $\varphi$ is the environmental correction factor, $\gamma$ is the average traveling speed correction factor, $\lambda$ is the vehicle deterioration correction factor and $\theta$ is the correction factor for other conditions (e.g., vehicle 
loading and fuel quality). Domestic tests on chemical compositions (Liu et al., 2008; Tsai et al., 2012; Huang et al., 2015; Wang et al., 2013; Ou et al., 2014; Gao et al., 2012) were incorporated to update the source profile of on-road vehicles. Lognormal distributions with CVs at 150 and $300 \%$ were, respectively, assumed for emission factors of on-road and off-road transportation.

\subsubsection{Oil distribution and other sources}

For oil distribution, Wei (2009) developed a simplified model to simulate the oil storage, transport and sale activities based on the provincial energy balance statistics, and the model was applied in this work to calculate the activity levels for the sector. Activity data from other sources were directly taken from official provincial statistics (NBS, 2015b, c). Emission factors of oil distribution and other sources were obtained from Wei et al. (2008) and Xia et al. (2014), and lognormal distributions were assumed for them as summarized in Table S4. The source profiles were obtained from Liu et al. (2008) and SPECIATE.

\section{Results}

\subsection{Source profiles of chemical industry from measurement}

NMVOC source profiles of 14 processes ( 9 for stack emissions and 5 for fugitive emissions) were obtained from field measurements. With a total of 61 species detected by GC-MS systems, the chemistry components were grouped into six types (alkanes, alkenes, halohydrocarbon, aromatics, OVOCs and others), as illustrated in Fig. 1a. Alkanes were the main species of synthetic rubber industry (SBR, SIS rubber and SEBS rubber), with the mass fractions over $70 \%$. For production of cellulose acetate fiber, alkanes, aromatics and OVOCs were the main species in the process of acetate flake production, while OVOCs dominated in the spinning process. Resulting from various raw materials, the source profiles of the two types of polyether production differed a lot: the mass fraction of OVOCs was close to $80 \%$ for polypropylene glycol (PPG), while the main species for polyether polyol (POP) were others, aromatics and halohydrocarbon. For ethylene production, aromatics mainly composed the stack gas of cracking furnace, while alkanes and alkenes dominated the fugitive emissions. For other types of fugitive emissions, big differences existed in the source profiles attributed mainly to the various raw materials and chemical reactions.

The detailed chemistry compositions for stack and fugitive emissions were summarized in Tables S5 and S6, respectively. For stack emissions of synthetic rubber production, cyclohexane was the dominating species, with the mass fractions close to or above $70 \%$ for all types of products. In addition, styrene and acetone were also important species for SBR and SIS/SEBS rubber, respectively. Used as the solvent in the chemical reactions, acetone and cyclohexane were considerably emitted during the acetate flake production process, and the mass fraction of acetone reached $70 \%$ in the spinning process. As the raw materials for polyether production, acrylonitrile and ethylene oxide were the main species emitted from POP and PPG production, with the mass fractions measured at 43 and $62 \%$, respectively. As the main product, vinyl acetate was measured to take $80 \%$ of NMVOC emissions from its production process. For fugitive emissions from ethylene production, the mass fractions of ethylene, propylene and n-hexane reached 33, 26 and $20 \%$, respectively. The 1,2-dichloropropane dominated the emissions from propylene oxide production, with the mass fraction measured at $65 \%$. For polyethylene and glycol production, ethylene and xylene were identified as the largest species, with the mass fractions measured at 42 and $35 \%$, respectively.

Since there were very few domestic tests on source profiles of chemical industry, the results obtained in this work were compared with those available in SPECIATE for synthetic rubber, ethylene and polyethylene production, as illustrated in Fig. 1b-d, respectively. As can be seen in Fig. 1b, large discrepancy was found for source files of SBR between this work and SPECIATE: while cyclohexane was identified as the main species in this work, SPECIATE included only styrene and 1,3-butadiene (the raw materials in SBR production). Variation in manufacturing technologies was the main source of the discrepancy. SPECIATE targeted emulsion polymerization technology in which solvents were not used, and NMVOC emissions consisted mainly of the volatile raw materials. This work, however, measured the plants with solution polymerization technology in which significant organic solvents would be released during the drying process. As shown in Fig. 1c, both SPECIATE and our measurements on fugitive emissions indicated that ethylene and isobutene were the important species for ethylene production. In addition, much larger fractions of propylene and $\mathrm{n}$-hexane were found in this work. Different compositions were found for flue gas of cracking furnace, with abundant species from incomplete combustion. Similar source profiles were found between this work and SPECIATE for polyethylene production, dominated by ethylene (Fig. 1d).

\subsection{Interannual trends and sectoral contribution of NMVOC emissions}

As shown in Table 3, the annual emissions of anthropogenic NMVOCs for Jiangsu were estimated to increase from 1774 to $2507 \mathrm{Gg}$ during 2005-2014, with an average annual growth rate at $3.9 \%$. Industrial processes and solvent use were identified as the largest two sectors contributing to the emissions. The emission fractions of the two types of sources to total anthropogenic emissions were estimated to increase from $26 \%$ in 2005 to $38 \%$ in 2014 and from 21 to $39 \%$, respectively. In contrast, emission contributions from 


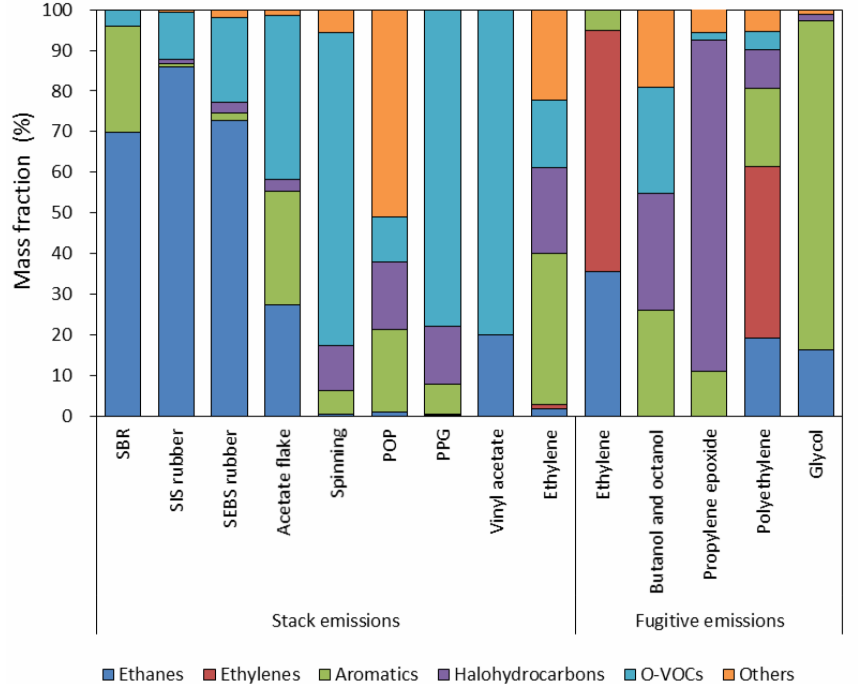

(a)

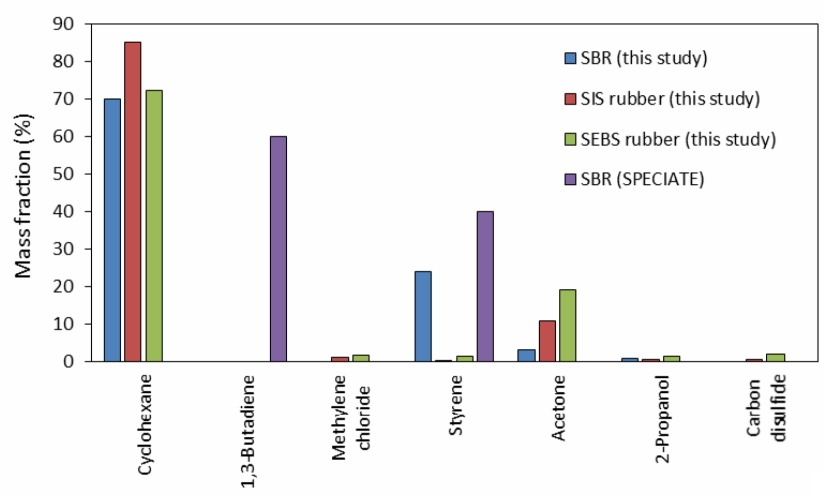

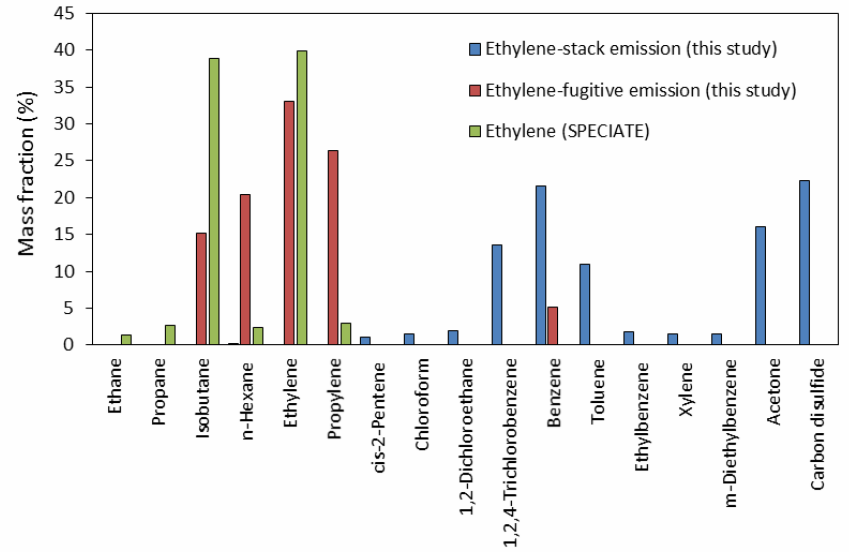

(c)

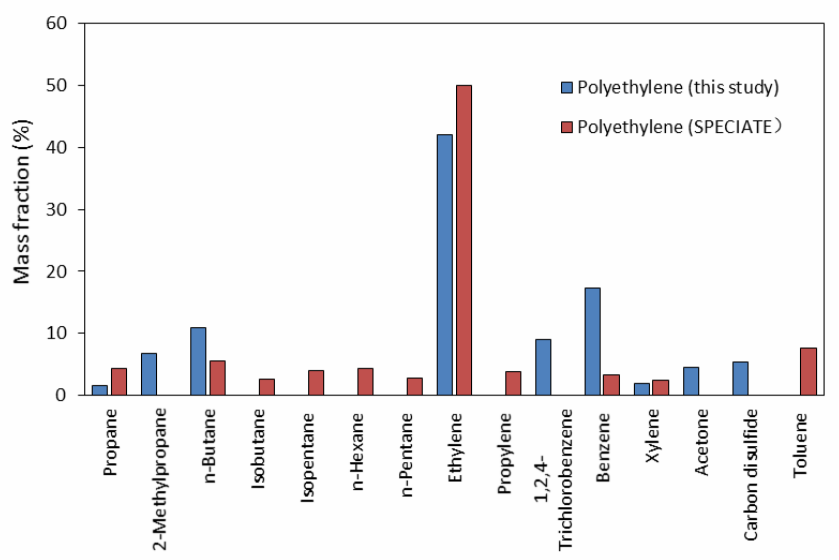

(d)

(b)

Figure 1. NMVOC source profiles by grouped species measured in chemical enterprises (a) and the comparisons with SPECIATE results for synthetic rubber (b), ethylene (c) and polyethylene production (d).

Table 3. Anthropogenic NMVOC emissions in Jiangsu by source from 2005 to 2014 (Gg).

\begin{tabular}{lrrrrrrrrrr}
\hline Source & 2005 & 2006 & 2007 & 2008 & 2009 & 2010 & 2011 & 2012 & 2013 & 2014 \\
\hline Fossil fuel combustion & 43 & 43 & 45 & 47 & 48 & 50 & 54 & 54 & 58 & 59 \\
Industrial process & 461 & 580 & 616 & 626 & 722 & 823 & 747 & 821 & 871 & 958 \\
Transportation & 325 & 321 & 336 & 331 & 331 & 317 & 313 & 302 & 311 & 280 \\
Solvent use & 380 & 441 & 492 & 495 & 606 & 652 & 697 & 783 & 809 & 966 \\
Oil distribution & 35 & 35 & 39 & 42 & 46 & 53 & 56 & 64 & 59 & 53 \\
Biomass burning & 458 & 343 & 355 & 147 & 139 & 131 & 126 & 119 & 116 & 110 \\
Other & 72 & 73 & 74 & 74 & 75 & 76 & 77 & 78 & 78 & 79 \\
Total & 1774 & 1835 & 1956 & 1762 & 1967 & 2102 & 2071 & 2220 & 2302 & 2507 \\
\hline
\end{tabular}

transportation and biomass burning declined from 18 to $11 \%$ and from 26 to $4 \%$, respectively, attributed mainly to the controlled motorcycle emissions, replacement of residential biofuel stoves with natural gas/electricity ones and the gradual implementation of straw-burning prohibition. Relatively small contributions were found for stationary fuel combustion plants, oil distribution and other sources, and their collective fractions to total emissions ranged $7-9 \%$ during the study period. 
Figure S3a-c in the Supplement provide the interannual trends in emissions of subcategories for industrial processes, solvent use and transportation. The emissions from industrial processes were estimated to double from 2005 to 2014, and the interannual trend in emissions was well correlated with that in industry GDP (Fig. S3a). The comprehensive investigations on point sources indicated that few measures were implemented to control NMVOCs until 2014, and the increased emissions were thus mainly driven by the growth of industry activities. The largest growth was found for synthetic and fine chemical industries, with the emissions elevated from 130 in 2005 to $361 \mathrm{Gg}$ in 2014. Due to enhanced coking industry, the emissions of iron and steel production were estimated to increase $254 \%$ from 27 to $96 \mathrm{Gg}$.

The emissions of solvent use in Jiangsu were calculated to increase $153 \%$ from 380 in 2005 to $963 \mathrm{Gg}$ in 2014, and the growth was highly consistent with that of industry plus construction GDP (Fig. S3b). Despite the increased use of watersoluble paint and implementation of emission standards for given processes (e.g., the VOC content of interior wall paint has been reduced from 250 to $120 \mathrm{~g} \mathrm{~kg}^{-1}$ since 2008), it was still difficult to restrain the emissions under the fast growth of solvent use, as relevant polices were not widely conducted across the sector. Paint use was the largest contributor, and its emissions were calculated to increase from 225 in 2005 to $652 \mathrm{Gg}$ in 2014. The emissions from printing ink increased $355 \%$ from 25 to $115 \mathrm{Gg}$.

Although Jiangsu's total vehicle population increased $76 \%$ from 2005 to 2014 , the NMVOC emissions of onroad transportation were estimated to decline $31 \%$ from 297 to $204 \mathrm{Gg}$, with the peak emissions at $302 \mathrm{Gg}$ in 2007 (Fig. S3c). The implementation of staged emission standards (State I-V, equal to Euro I-V) on new vehicles and the reduced motorcycle population were the main reasons for the declining emissions. For example, emissions of motorcycles deceased $66 \%$ from 185 to $64 \mathrm{Gg}$, and their contribution to on-road vehicle emissions declined as well from 62 to $31 \%$. Gasoline vehicles dominated the emissions of on-road transportation, with the fraction ranging $81-87 \%$ during the study period.

Illustrated in Fig. 2 are the spatial distributions of Jiangsu's NMVOC emissions for various years within a $3 \times 3 \mathrm{~km}$ grid system. The emissions of point sources were directly allocated according to their geographic locations. For other sources, certain proxies were applied to allocate emissions, including GDP for industrial area sources and oil distribution, population for solvent-use area sources, road net and traffic flow for on-road vehicles, railway and canal net for off-road transportation and rural population for biomass burning. High emission intensities were mainly found in relatively developed cities along the Yangtze River in southern Jiangsu including Nanjing, Suzhou, Wuxi and Yangzhou (see Table S7 for the emissions by city). In central and northern Jiangsu, large emissions existed in areas with clustered industrial parks, reflecting the impacts of big plants on the spatial pattern of NMVOC emissions. Comparing the emissions for 2005 and 2014, increased emissions were commonly found in southern Jiangsu, indicating the faster growth of industry in developed cities (Fig. 2d). Moreover, reduced emissions coincided with road net distribution, implying the benefit of emission controls on vehicles.

\subsection{Speciation and OFPs of NMVOC emissions}

Table 4 compares the source profiles of this work with those of Li et al. (2014) or SPECIATE for typical source categories, grouped as alkanes, alkenes, alkynes, aromatics, OVOCs and others. Elevated fractions of alkanes are found in this work for almost all the sources, while the comparisons of other species are less conclusive between sources. Based on the source profiles, emissions of more than 500 NMVOC species were calculated and grouped into 12 categories (alkanes, alkenes, alkynes, aromatics, alcohols, aldehydes, ketones, ethers, acids, esters, halohydrocarbons and others). From 2005 to 2014, the mass fractions of alkanes, unsaturated hydrocarbon (alkenes and alkynes), aromatics, OVOCs (alcohols, aldehydes, ketones, ethers, acids and esters), halohydrocarbons and others were between 26-30, 13-19, 21-23, $18-21,3-4$ and $11-12 \%$, respectively.

Shown in Fig. 3 are the mass fractions of species by source category for 2014. Due to varied fuel qualities and combustion conditions, large differences in emission speciation were found for fossil fuel combustion, transportation and biomass burning. The profile of fossil fuel stationary sources was dominated by coal combustion, and aromatics were the largest fraction $(45 \%)$, followed by alkanes $(29 \%)$. Alkanes, aromatics and alkenes were the main species from transportation, with the fractions estimated at 30, 24 and $23 \%$, respectively. For biomass burning, elevated alkenes and less alkanes were found attributed to the highly incomplete combustion. The mass fractions of alkanes, aromatics and alkenes from industrial processes were estimated 32,16 and $12 \%$. In particular, relatively close emission fractions were found between species for the chemical industry, the largest emission source of industrial processes, i.e., 19, 15, 11, 10 and $10 \%$ for aromatics, ketones, alkenes, alkanes and halohydrocarbons, respectively. For solvent use, aromatics and alkanes were the most important species with the fractions estimated at 32 and $22 \%$, respectively, and the collective fraction of OVOC species reached $27 \%$. Alkanes and aldehydes dominated the emissions of oil distribution and other sources, which came mainly from the oil evaporation and residential cooking, respectively.

The OFPs from NMVOC emissions in Jiangsu were calculated to increase from 3880 in 2005 to $5200 \mathrm{Gg}$ in 2014 , and the ratio of annual OFPs to emissions varied slightly around 2.1 for the decade. As the chemical profiles of emitted NMVOCs vary between source categories, the OFP-toemission ratio for a given category could indicate the potential contribution to ozone formation of the category, as a 


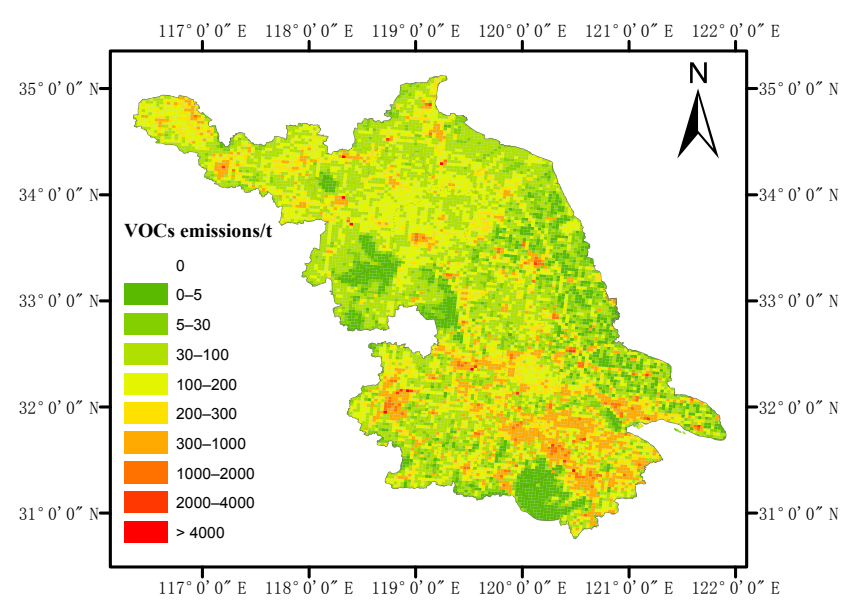

(a) 2005

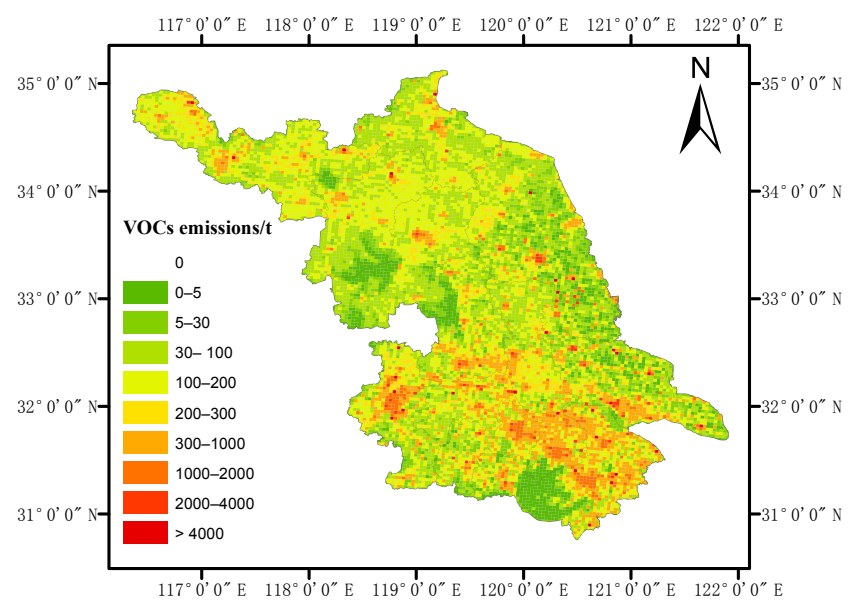

(c) 2014

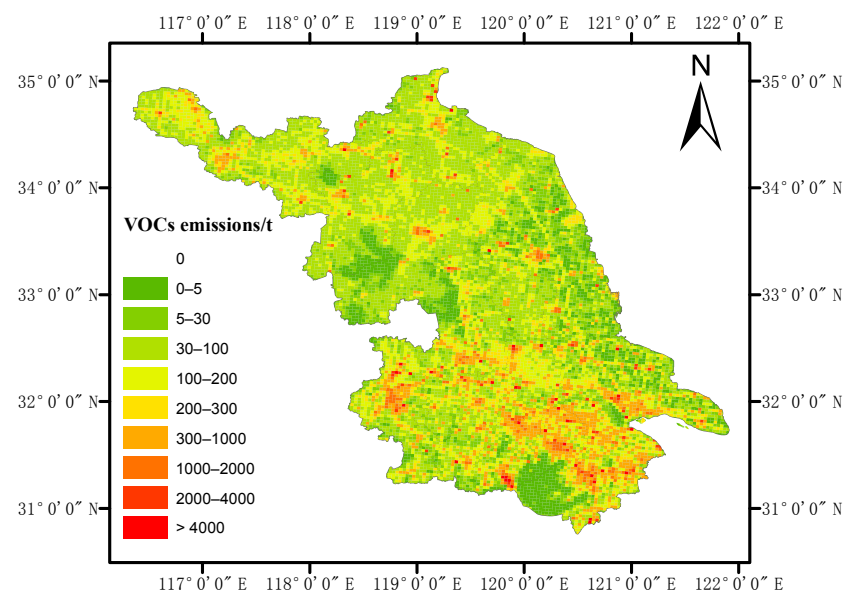

(b) 2010

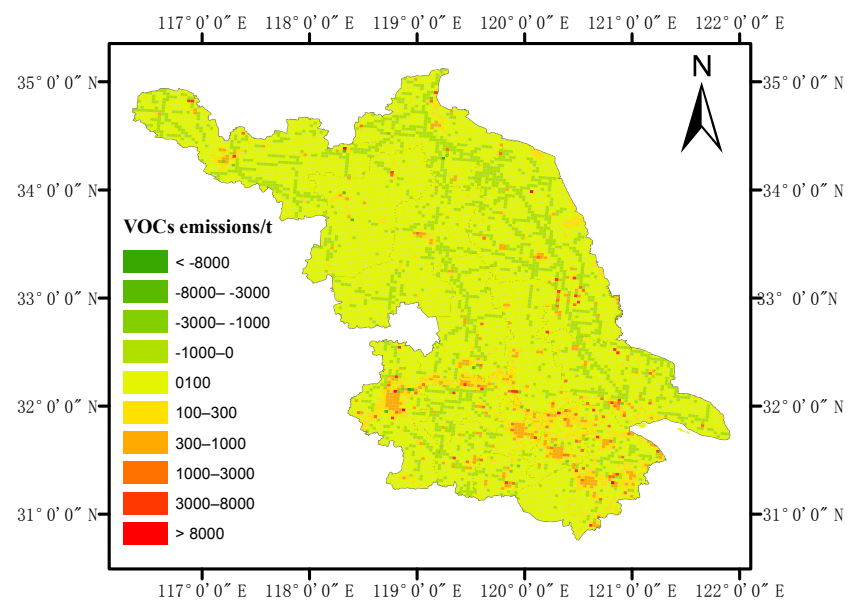

(d) Difference between 2005 and 2014

Figure 2. Spatial distribution of Jiangsu's anthropogenic NMVOC emissions $(3 \times 3 \mathrm{~km})$ for 2005 (a), 2010 (b) and 2014 (c), and the differences between 2005 and 2014 (2005 data subtracted from 2014 data; d).

combined effect of multiple species emitted. The priorities of emission control for ozone abatement could thus be suggested by the ratio. The ratios for 2014 were provided by source in Fig. 3. With abundant aromatic and alkene emissions that were highly active in chemistry, the largest ratio (3.68) was found for fossil fuel stationary combustion. The ratios of biomass burning and other sources reached 3.0, attributed to active aromatic and aldehyde emissions, respectively. The lowest ratio (1.58) was found for oil distribution, as its emissions were dominated by alkanes with low reactivity. Figure S4 in the Supplement provided 25 species with the biggest contributions to OFPs and their emission sources for 2005 and 2014. In 2005, the 25 species were estimated to account for $44 \%$ of total NMVOC emissions and $83 \%$ of OFPs (Fig. S4a). Xylene, ethylene and propylene were identified as the most three important species in terms of OFP. The aromatic species with (e.g., xylene and toluene) came largely from solvent use and industrial processes, while alkene species (e.g., ethylene and propylene) were mainly from industrial processes, biomass burning and transportation. In addition, biomass burning was the dominating sources of methyl glyoxal, methyl alcohol and glyoxal. For 2014, the 25 species were estimated to account for $38 \%$ of total NMVOC emissions and $81 \%$ of OFPs, and the contributions of solvent use and industrial processes to OFPs were clearly elevated (Fig. S4b). The orders of isopropanol and n-butanol that were mostly from solvent use, for example, were moved forward. Moreover, the contribution of biomass burning significantly declined, and the glyoxal was not identified as one of the 25 most important species to OFPs any more. 
Table 4. Updated NMVOC source profiles in this study and those from SPECIATE and Li et al. (2014).

\begin{tabular}{|c|c|c|c|c|c|c|c|}
\hline \multirow[t]{2}{*}{ Sector } & & \multicolumn{6}{|c|}{ Species (weight percentage, \%) } \\
\hline & & Alkanes & Alkenes & Alkynes & Aromatics & OVOCs & Others \\
\hline \multirow[t]{2}{*}{ Biomass open burning } & This study & 14.83 & 17.24 & 2.20 & 10.98 & 52.58 & 2.16 \\
\hline & SPECIATE & 14.20 & 20.59 & 2.62 & 1.82 & 57.68 & 3.08 \\
\hline \multirow[t]{2}{*}{ Coking } & This study & 25.65 & 25.00 & 1.34 & 25.42 & 1.43 & 21.16 \\
\hline & SPECIATE & 9.17 & 39.45 & 2.14 & 49.24 & 0.00 & 0.00 \\
\hline \multirow[t]{2}{*}{ Iron and steel } & This study & 25.64 & 11.23 & 15.56 & 13.60 & 2.36 & 31.62 \\
\hline & SPECIATE & 28.06 & 16.67 & 27.72 & 0.00 & 0.00 & 27.56 \\
\hline \multirow[t]{2}{*}{ Paint production } & This study & 3.90 & 0.00 & 0.00 & 48.61 & 42.76 & 4.72 \\
\hline & SPECIATE & 0.00 & 0.00 & 0.00 & 80.65 & 19.35 & 0.00 \\
\hline \multirow[t]{2}{*}{ Ink production } & This study & 54.48 & 15.27 & 0.00 & 30.25 & 0.00 & 0.00 \\
\hline & SPECIATE & 5.00 & 0.00 & 0.00 & 6.50 & 63.00 & 25.50 \\
\hline \multirow[t]{2}{*}{ Refinery } & This study & 77.02 & 12.10 & 0.00 & 10.89 & 0.00 & 0.00 \\
\hline & Li et al. (2014) & 67.57 & 9.44 & 0.91 & 1.96 & 0.00 & 20.12 \\
\hline \multirow[t]{2}{*}{ Furniture painting } & This study & 6.15 & 0.14 & 0.00 & 61.61 & 29.23 & 2.87 \\
\hline & SPECIATE & 0.00 & 0.00 & 0.00 & 30.00 & 51.42 & 18.58 \\
\hline \multirow[t]{2}{*}{ Architecture painting } & This study & 28.69 & 9.39 & 0.00 & 61.92 & 0.00 & 0.00 \\
\hline & Li et al. (2014) & 27.48 & 4.71 & 0.00 & 67.81 & 0.00 & 0.00 \\
\hline \multirow[t]{2}{*}{ Vehicle varnish paint } & This study & 3.65 & 0.55 & 0.06 & 59.09 & 32.02 & 4.64 \\
\hline & Li et al. (2014) & 2.14 & 0.82 & 0.08 & 96.96 & 0.00 & 0.00 \\
\hline \multirow[t]{2}{*}{ Printing } & This study & 29.54 & 2.90 & 0.69 & 16.64 & 44.89 & 5.33 \\
\hline & Li et al. (2014) & 14.78 & 2.79 & 0.66 & 11.03 & 26.96 & 43.78 \\
\hline \multirow[t]{2}{*}{ Diesel vehicle } & This study & 44.30 & 22.41 & 1.79 & 20.10 & 11.39 & 0.00 \\
\hline & Li et al. (2014) & 14.88 & 11.60 & 0.83 & 8.99 & 48.99 & 14.71 \\
\hline \multirow[t]{2}{*}{ Motorcycle } & This study & 41.36 & 23.36 & 2.11 & 28.50 & 4.68 & 0.00 \\
\hline & Li et al. (2014) & 45.88 & 32.18 & 0.56 & 21.37 & 0.00 & 0.00 \\
\hline
\end{tabular}

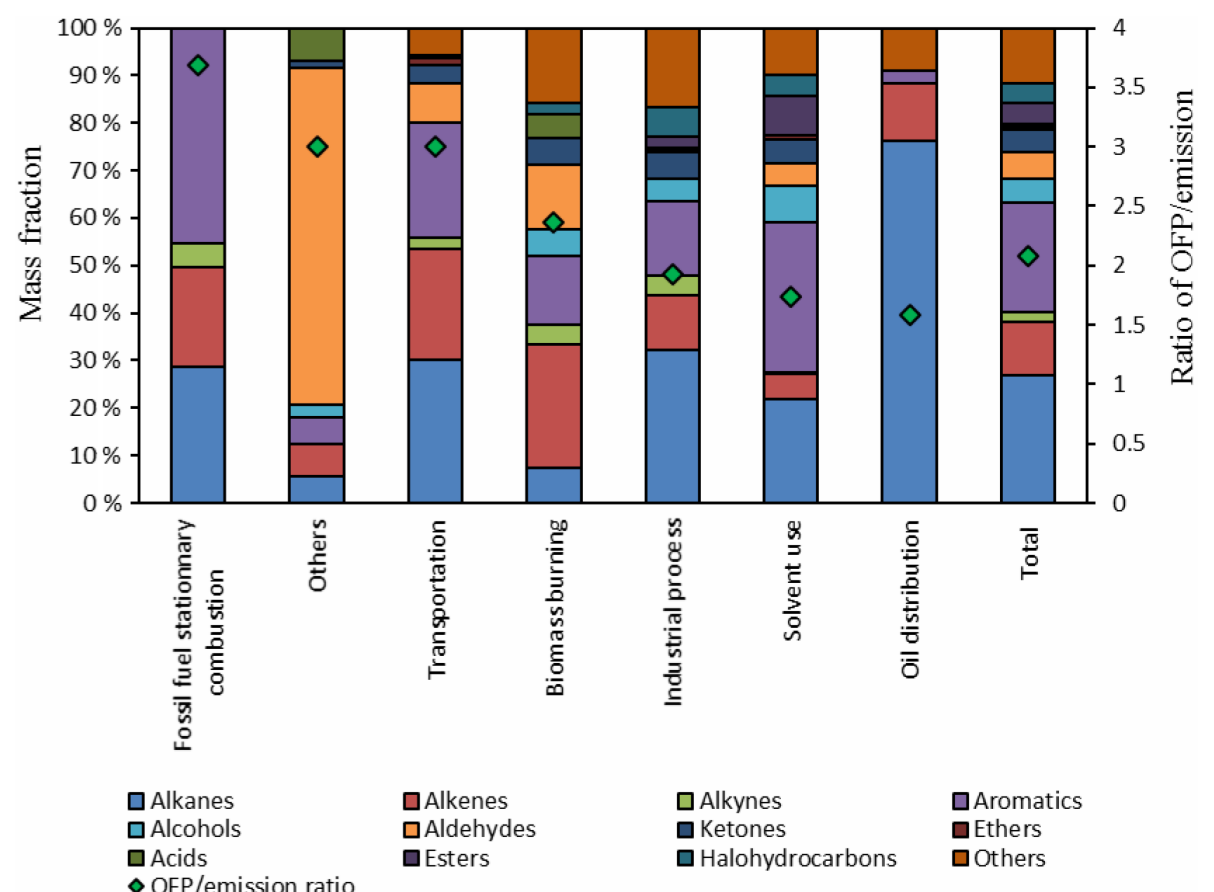

Figure 3. Fractions of NMVOC species and the ratios of OFPs to emission by sector for Jiangsu in 2014. 


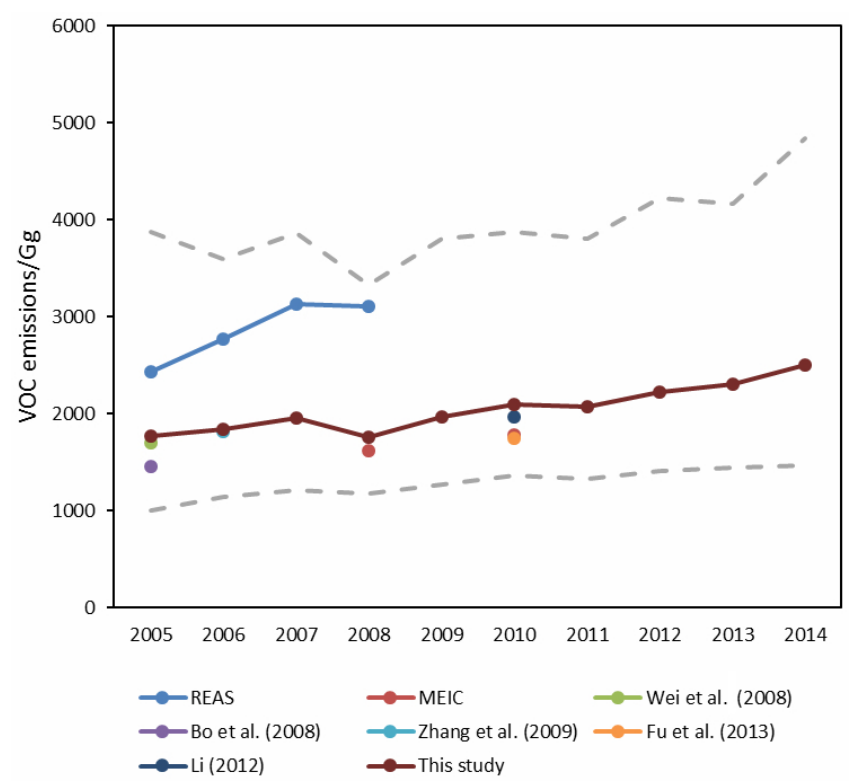

Figure 4. The interannual trends in anthropogenic NMVOC emissions in Jiangsu from 2005 to 2014. The grey dotted lines indicate the $95 \%$ CIs of emissions estimated in this study. The results from other inventories are illustrated as well for comparison.

\subsection{Uncertainties of provincial NMVOC emission inventory}

The uncertainties of estimated annual NMVOC emissions for Jiangsu in 2005-2014 are illustrated in Fig. 4, expressed as the $95 \%$ confidence intervals (CIs) around the central estimates. As interannual changes were hardly assumed in probability distributions for parameters, similar uncertainty ranges were calculated for emissions of various years. As shown in Table 5, the uncertainty of emissions for 2014 was quantified at -41 to $+93 \%(95 \% \mathrm{CI})$, and biomass burning and other sources were estimated as the sources with largest uncertainties, followed by stationary fossil fuel combustion and oil distribution. For most emission sectors/categories, emission factors were identified as the largest sources of emission uncertainty, with an exception of solvent use. Resulting from complicated sources of stack and fugitive emissions, it is generally difficult to conduct comprehensive field tests on emission factors for industrial and residential sources. As described in Sect. 2.3, large uncertainties had to be conservatively assumed for them due to limited domestic samples and heavy dependence on foreign databases. More measurements on actual emission characteristics are thus recommended to expand data samples for better evaluating the PDFs and effectively reducing emission uncertainty. Regarding solvent use, which provincial and city statistics were lacking, the activity data had to be downscaled from national level leading to possibly a big bias in emission estimation.

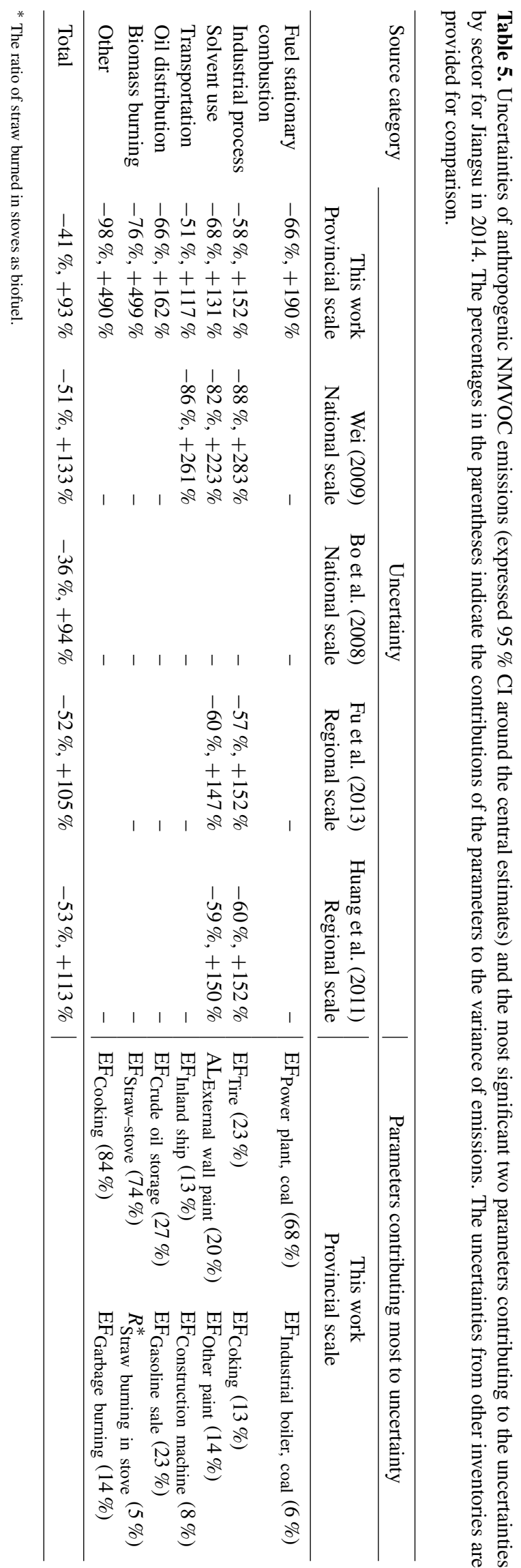

www.atmos-chem-phys.net/17/7733/2017/ 
Also provided in Table 5 are the uncertainties of national and YRD emissions from other studies. Note that all the studies applied the Monte Carlo simulation except that of Huang et al. (2011), which calculated the uncertainty of emissions based on the predetermined CVs of emission factors and activity levels at sector level. Compared with those results, the emission uncertainties were reduced in this work for industrial processes, solvent use and transportation. Besides the varied methods and assumptions of PDFs for relevant parameters, the more detailed classification of emission sources and adoption of independent emission factors for those sources should be an important reason. For example, in total, 34 vehicle-type control combinations were taken into account for calculating the on-road vehicle emissions, and the emission factor for each type of combination was assumed independent from the others. In addition, the errors of activity levels for big point sources were significantly reduced from the detailed investigation and on-site surveys at plant level, leading to smaller uncertainty in emission estimation for industrial and solvent-use sources.

\section{Evaluation of provincial emission inventory}

\subsection{Chemical and refinery industry emissions from varied data sources and methods}

As a part of the industrial processes, chemical and refinery industries were one of the biggest contributors to anthropogenic NMVOC emissions. We select Nanjing, the capital city of the Jiangsu province, to evaluate the impacts of data sources and methods on emissions of this category. As described in Sect. 2.2 and 2.3, the method used in this work for provincial inventory improvement incorporated the most available information from environmental statistics, PSC and on-site surveys (named Method 1 here). In addition, two other methods based, respectively, on data from environmental statistics (Method 2) and economic statistics without any information on individual plants (Method 3, which was commonly applied in national and regional inventories) were also applied to calculate the emissions in the city for 2011, and the results with different methods were compared against each other. Note that the emissions of area sources (i.e., not included in plant-by-plant investigations) in Methods 1 and 2 were the same as in Method 3. Table S8 in the Supplement provides the emissions calculated based on the three data sources by the subcategory of the chemical and refinery industries. The emissions estimated using Method 1 were clearly larger than those using Methods 2 or 3, resulting mainly from the incomplete records of chemical products by environmental or economic statistics. For example, some basic chemistry products (e.g., ethylene oxide and ethylene glycol) and synthetic chemical products (e.g., polyether and polyethylene) were not included in current economic statistics. In addition, although most chemical and refinery plants were investigated in the environmental statistics, only three types of chemical products were recorded for each plant, much less than the actual amount (more than 100 types for some plants). The omission of chemical product types thus led to underestimations in NMVOC emissions. With the product types fully covered, Method 1 could even underestimate the emissions, as the emission factors could not be measured or determined for all products due to the completed pipe layout or fugitive release.

Spatial distributions of the emissions in the three methods are illustrated in Fig. 5. Similar patterns were found for Methods 1 and 2 (Fig. 5a and b), as the emissions were dominated by the big chemical and refinery plants. As labeled in Fig. 5a, the largest 10 plants were estimated to account for $80 \%$ of NMVOC emissions of the sector for the whole city. Without detailed information of individual plants, Method 3 had to apply the proxies (e.g., population density) to allocate the emissions and would overestimate the fraction of emissions in urban downtown (Fig. 5c). The comparison indicated the possible errors in spatial distribution of emissions at small scale when emissions were downscaled from larger scale without sufficient investigation of local sources, particularly for regions where large plants were gradually moved out of urban areas.

To further examine the emission estimation on individual plants, an alternative method was applied to calculate the emissions of all manufacturing processes separately, including leaks of hydrocarbon vapors from process equipment (valves, flanges, seals, etc.), storage of organic liquid, loading and unloading of organic liquid and waste water treatment (mentioned as the device-operation-based method herein). As indicated in Table S9 in the Supplement, detailed information of $15 \mathrm{key}$ chemical and refinery enterprises in Nanjing (i.e., enterprises directly under the control of the city government) were collected and the emissions of those plants were calculated and compared with the results using the method as described in Sect. 2.2 and 2.3 (mentioned as the emission-factor-based method herein). Although the total emissions of the 15 plants were very close between the two methods, significant discrepancies existed for individual plants. For example, much larger NMVOC emissions were calculated for plants 3 and 6 with the device-operation-based method, as the emission factors for production of chlorobenzene alkylbenzene and cyclohexanone were lacking, leading to underestimation of the emission-factor-based method. As shown in Fig. S6 in the Supplement, the differences in emissions from varied calculating methods for the 15 plants led to moderate changes in spatial distributions of the chemical and refinery emissions for the city. In general, the deviceoperation-based method could better capture the activities of specific plant and the actual emission characteristics; however, the method could hardly be applied in a broader scale, as it depends strongly on the completeness and quality of data collection. 


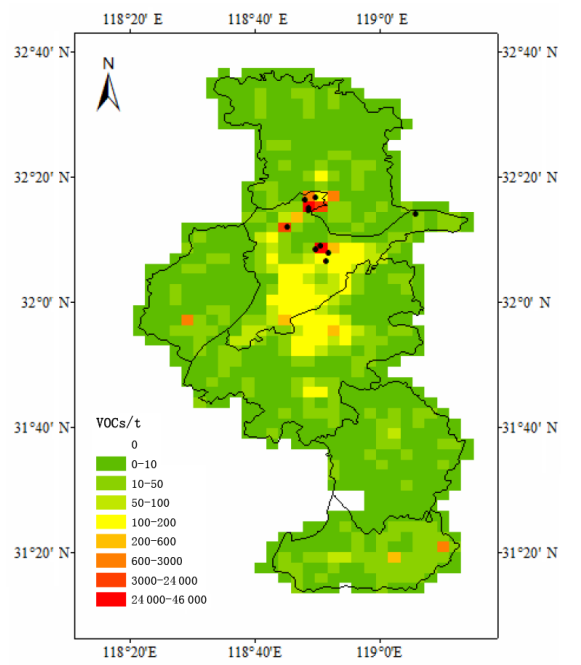

(a)

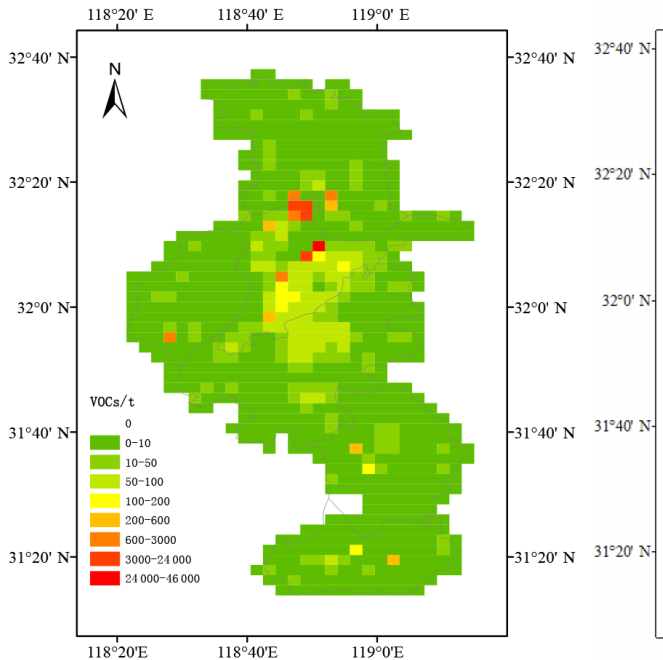

(b)

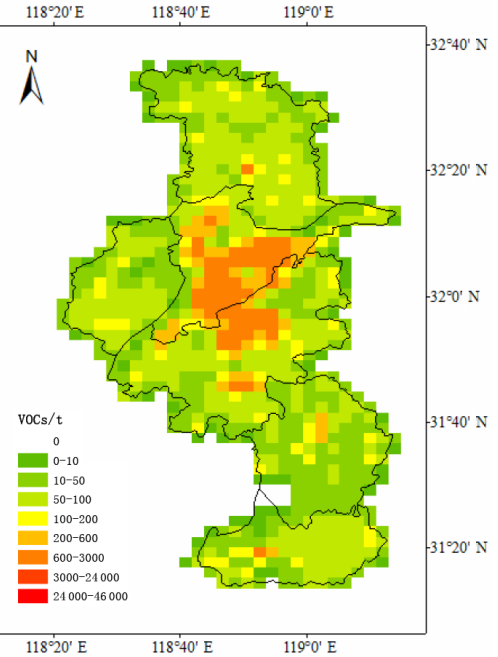

(c)

Figure 5. Spatial distributions of NMVOC emissions from the chemical and refinery industries for Nanjing $2011(3 \times 3 \mathrm{~km})$, estimated using the detailed enterprise information (a), environmental statistics (b) and economic statistics without any information on individual sources (c). The black dots indicate the largest 10 emitters in the city

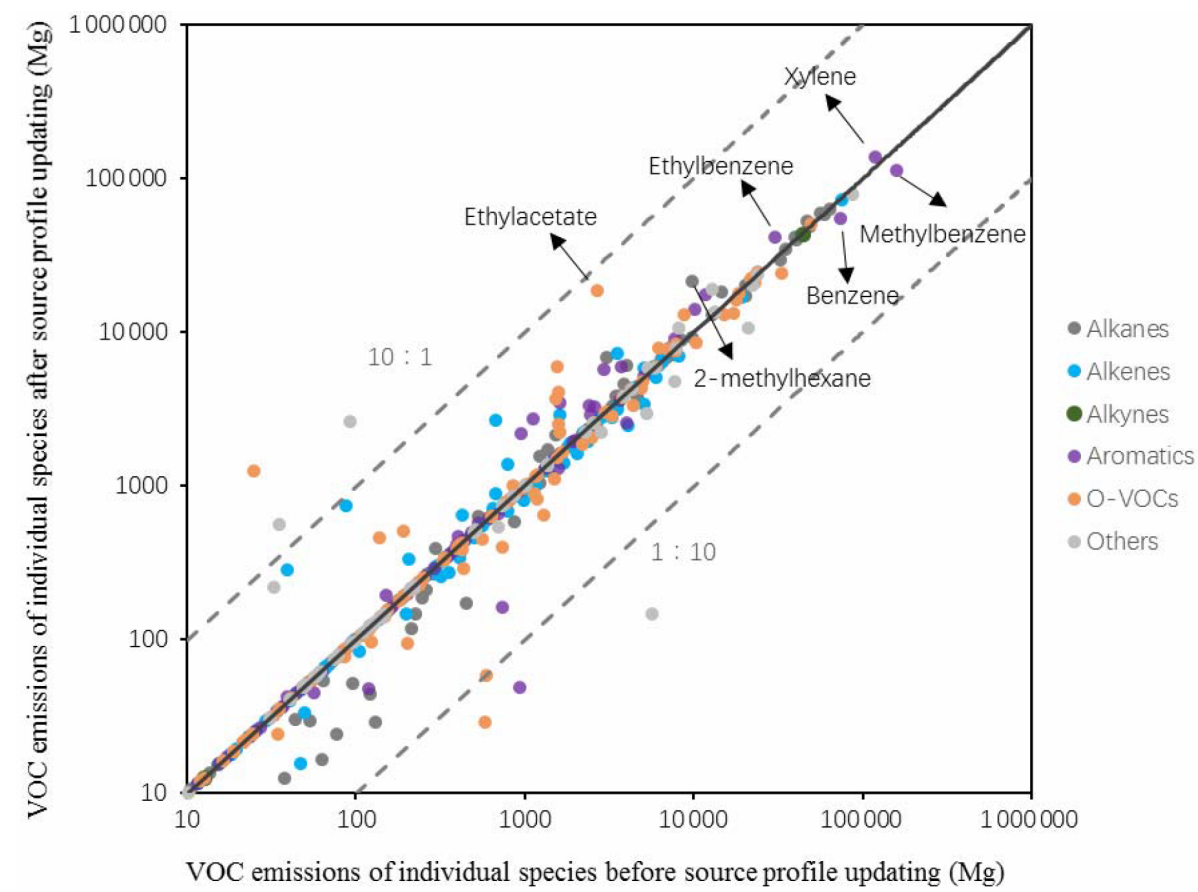

Figure 6. Emissions of NMVOC species for Jiangsu in 2010 before and after source profile updating.

\subsection{Changes in speciation of NMVOC emissions}

As indicated in Sect. 2.2, the speciation of NMVOC emissions in Jiangsu were updated by including our measurements and other more recent domestic tests after 2010, based on the combined profile of Li et al. (2014) and SPECIATE (i.e., the source profile before updating). The source types we measured accounted for 9-11\% of annual NMVOC emissions from chemical industry and refinery for Jiangsu in 2005-2014. In particular, the contribution of those sources was enhanced in typical cities with intensive chemical industry. In Nanjing, as an example, the source categories we measured accounted for $19 \%$ of annual emissions from chemical industry and refinery, and for $10 \%$ of the total anthro- 
pogenic emissions in 2010. Figure 6 illustrates the emissions of 445 species (accounting for $99.5 \%$ of total NMVOC emissions) estimated with the source profile before and after updating for Jiangsu in 2010. As a whole, the difference between emissions of all species before and after updating was calculated at $281 \mathrm{Gg}$, i.e., $13 \%$ of the total anthropogenic NMVOC emissions for the province. Due to relatively limited tests available, the changes in emissions were small for most species when updated profiles were applied. Relatively big changes (over $10 \mathrm{Gg}$ ) were found for ethylacetate and certain aromatic species (benzene, xylene, ethylbenzene and methylbenzene). Applying the source profile of paint use measured by Zheng et al. (2013) led to enhanced ethylacetate. Reduced benzene and methylbenzene, and elevated ethyl benzene and xylene resulted mainly from the revisions on source profiles of cooking (Jia et al., 2009; Shi et al., 2015) and solvent use (H. Wang et al., 2014b; Zheng et al., 2013). Although incremental information on speciation was obtained through the on-site measurements and source profile updating in current work, domestic data were still lacking for many source types, given the big variety of source categories for industrial process and solvent use. Therefore, more efforts in field measurements are still needed in order to establish a more complete database of chemical profiles for the country and the region.

To support the air quality modeling, the emissions of NMVOC species under CB05 and SAPRC99 mechanisms were calculated using Eq. (4) based on the source profiles before and after updating, and the results for 2010 were shown in Fig. 7 (the speciation for MEIC is illustrated in the figure as well for comparison, as discussed later in Sect. 4.3). With source profiles updated based on the most recent measurements, relatively big changes were found for ALDX (see the caption of Fig. 7 for the detailed meanings) in CB05 and OLE1 in SAPRC99. The revisions of source profiles of solvent use were the main reason for the changes. For example, the increased ALDX was attributed mainly to the updated profiles of printing ink and automobile paint use (Zheng et al., 2013), while increased OLE1 to that of building coating (Yuan et al., 2010; H. Wang et al., 2014b).

\subsection{Comparisons with other inventories}

The total anthropogenic NMVOC emissions in Jiangsu were extracted from other continental/national/regional inventories and compared with our estimates for various years in Fig. 4. All the results were within the $95 \%$ CIs in this work. Except for REAS, which provided 37-77\% higher emissions than this work for 2005-2008 (Kurokawa et al., 2013), our estimates were generally $0-18 \%$ larger than other studies in the total emission estimation, attributed mainly to the omission of certain emission sources in other inventories and to the elevated activity levels from plant-by-plant investigation in this work. Figure 8 provided the NMVOC emissions by source from various inventory studies for selected years. As can be seen, the emissions in this work were 4 and $20 \%$ larger than the national inventory for 2005 (Wei et al., 2008) and regional inventory for 2010 (Fu et al., 2013), respectively. The latter two studies missed the emissions from the manufacturing processes of certain chemical products. For example, fermentation alcohol, dye and rubber were not included in Wei et al. (2008), and glasswork, pesticide and charcoal were not included in Fu et al. (2013). The emissions from solvent use in this work were larger than those from Bo et al. (2008), attributed to omission of carpentry coating, pesticide and adhesive use by the latter. The varied data sources also contributed to the emission discrepancies. For example, Wei et al. (2008) and Bo et al. (2008) made larger estimates in transportation emissions than we did, as they applied higher values of annual average miles traveled for motorcycles at national level.

The emissions of CB05 and SAPRC 99 species estimated by us and MEIC were compared in Fig. 7. While total NMVOC emissions in this work were $315 \mathrm{Gg}$ or $18 \%$ larger than MEIC for 2010, relative changes varied among species and could be bigger for certain species. In the CB05 mechanism, our results were 46 and $43 \%$ smaller for TOL and XYL but 38 and $59 \%$ larger for ETH and ETHA than MEIC (Fig. 7a), while discrepancies of over $30 \%$ (relative to MEIC) existed for most species in SAPRC 99 (Fig. 7b). Such discrepancies could result either from the various source profiles or from the various source contributions to total emissions. For example, with the updated source profile for building coating, much larger OLE1 emissions were estimated in this work than in MEIC. Besides the total emissions, the different speciations under chemical mechanisms could result in complex impacts on air quality simulation and will be discussed in next section.

Figure 9 compares the spatial distributions of Jiangsu's NMVOC emissions for 2010 between our results and MEIC. To be consistent in resolution and to ease visualization, the high-resolution inventory obtained in this work (Fig. 2) was upscaled to $0.25^{\circ} \times 0.25^{\circ}$, the same as MEIC. Similar spatial patterns were found for the two inventories: high emission densities existed in southern Jiangsu with relatively developed economy and industry. As indicated in Fig. 9a, the areas with big plants and large emissions were consistent with each other, indicating that the provincial NMVOC emissions were largely influenced by the locations of large point sources. Figure 9c shows that larger emissions estimated in this work than MEIC were commonly found in areas with big plants, reflecting the impacts of complete investigation of product types and activity levels at plant level on the emission estimation. Although our result was $18 \%$ larger than MEIC in total anthropogenic NMVOC emissions, lower emissions were found in this work in downtown Nanjing and the SuzhouWuxi-Changzhou city clusters with large populations. The result implies that downscaling of emissions depending on certain proxies (e.g., population and economy density) might 
(a) CB05

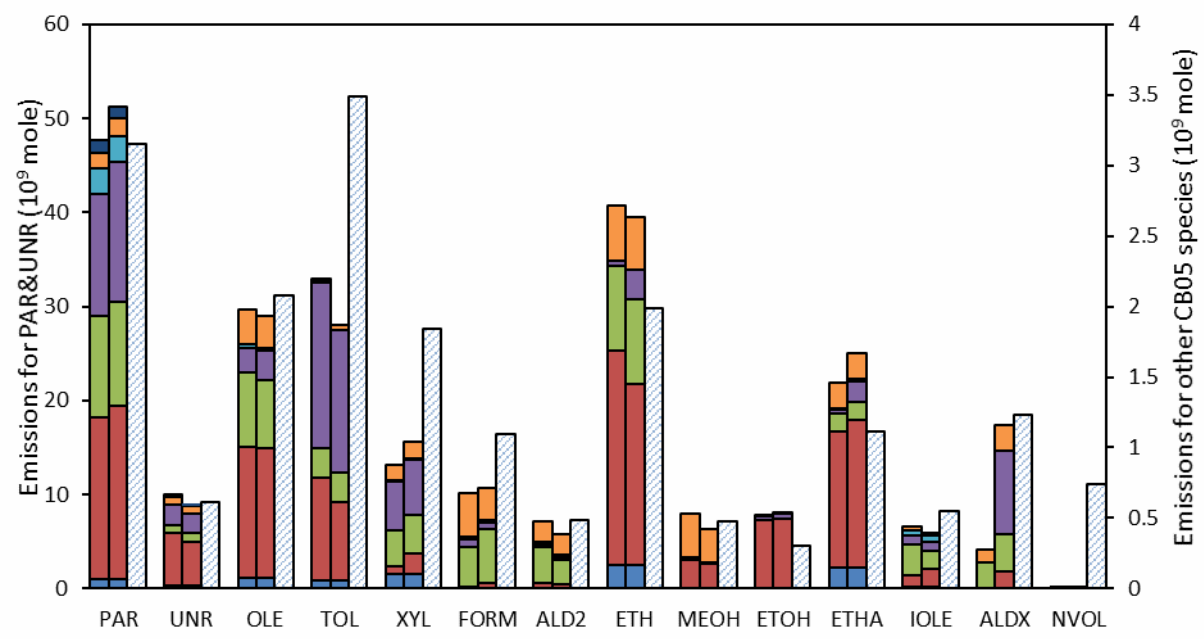

(b) SAPRC99

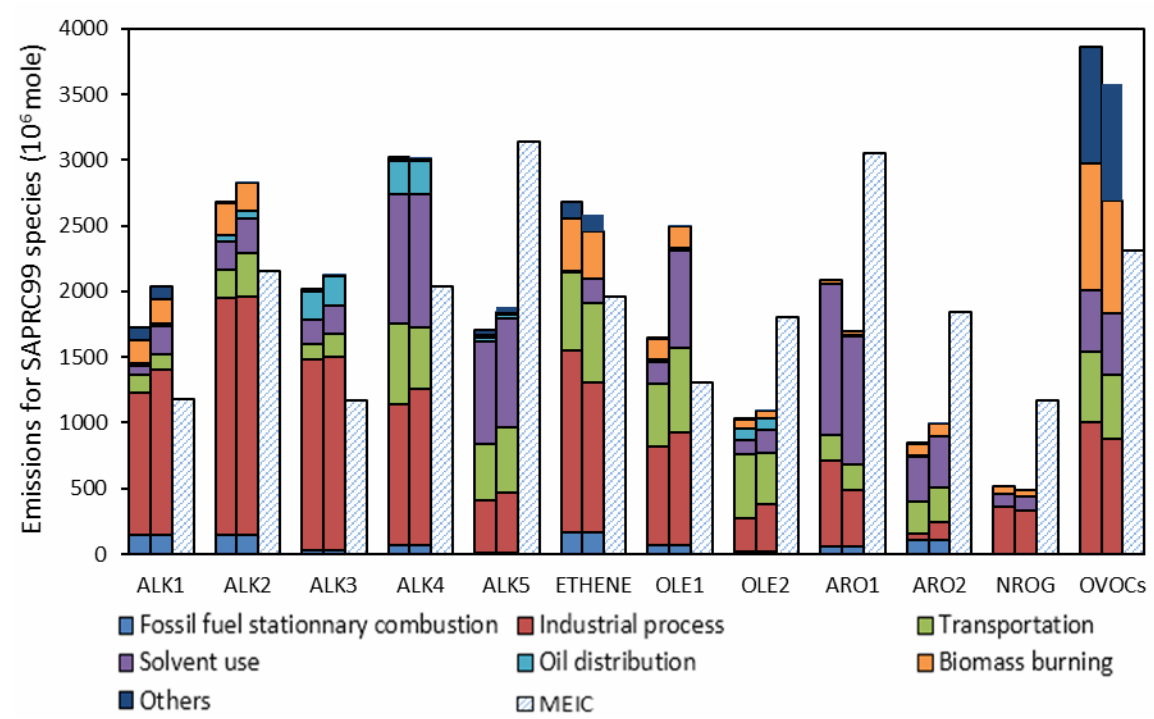

Figure 7. Emissions of CB05 (a) and SAPRC99 (b) species for Jiangsu in 2010. The left and middle columns indicate the results before and after updating of source profiles, and the right columns indicate the results of MEIC. The CB05 species PAR stands for the paraffin carbon bond, UNR for unreactive parts of molecules, OLE for terminal olefin carbon bond, TOL for toluene and other monoalkyl aromatics, XYL for xylene and other polyalkyl aromatics, FORM for formaldehyde, ALD2 for acetaldehyde, ETH for ethene, MEOH for methanol, ETOH for ethanol, ETHA for ethane, IOLE for internal olefin carbon bond, ALDX for C3+ aldehydes and NVOL for non-volatile mass. The SAPRC 99 species ALK1, ALK2, ALK3, ALK4 and ALK5 represent alkanes and other non-aromatic compounds that react only with OH and have kOH between 2 and 500, 500 and 2500, 2500 and 5000, 5000 and 10000, and greater than $10000 \mathrm{ppm}^{-1} \mathrm{~min}^{-1}$, respectively. ETHENE stands for

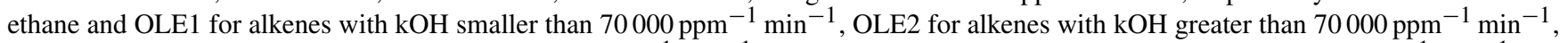
ARO1 for aromatics with $\mathrm{kOH}$ smaller than $20000 \mathrm{ppm}^{-1} \mathrm{~min}^{-1}$, ARO2 for aromatics with $\mathrm{kOH}$ greater than $20000 \mathrm{ppm}^{-1} \mathrm{~min}^{-1}$ and NROG for unreactive mass.

overestimate the emissions in urban areas, and detailed information on individual sources should be included if possible.

\subsection{Evaluation of multiple-scale inventories through air quality modeling}

The Models-3/Community Multi-scale Air Quality (CMAQ) version 4.7.1 was applied to test the performance of chemistry transport simulations with various NMVOC emission inventories for the Jiangsu area. As shown in Fig. S6 in the 


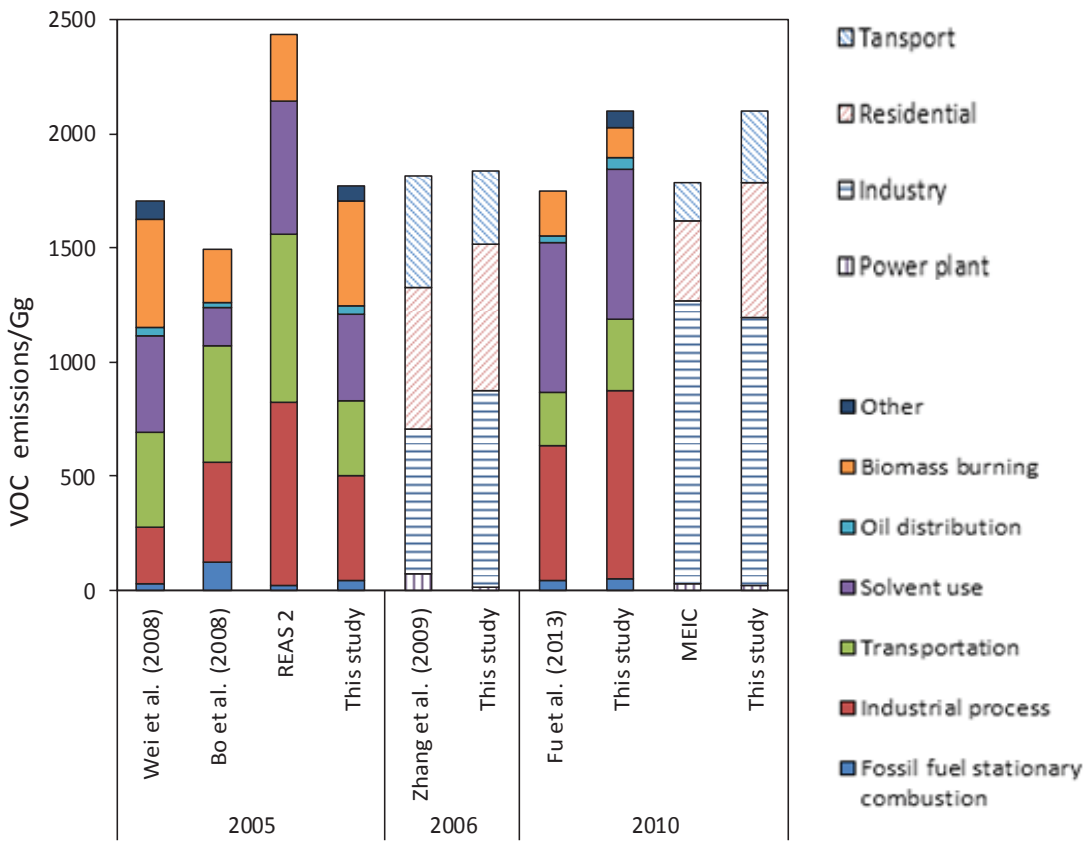

Figure 8. Jiangsu's anthropogenic NMVOC emissions by sector for selected years estimated from this work and other inventories. Note that emissions in this work are regrouped to be consistent in source categories with Zhang et al. (2009) and MEIC for direct comparison.

Supplement, three nested domains (D1, D2 and D3) were set, and the most inner D3 covered the megacity Shanghai and the six most developed cities in southern Jiangsu including Nanjing, Changzhou, Zhenjiang, Wuxi, Suzhou and Nantong, with a horizontal spatial resolution at $3 \mathrm{~km}$. Chemistry transport simulations were conducted separately with two inventories, i.e., MEIC and the provincial inventory developed in this work, for January, April, July and October 2012. Other model settings on meteorological simulation, chemistry mechanisms and emissions of natural origin were the same for the two simulations, as described in Zhou et al. (2017). The first 5 days for each month were chosen as the spin-up period to provide initial conditions for later simulations.

Figure 10 provides the observed and predicted daily $1 \mathrm{~h}$ maximum $\mathrm{O}_{3}$ concentrations for the 4 months, and Table 6 compares the model performance with MEIC and our provincial inventory, indicated as normalized mean bias (NMB) and error (NME) values. As suggested by the negative NMBs for most cases, the model usually generated lower $1 \mathrm{~h}$ maximum $\mathrm{O}_{3}$ concentrations than the observation with either MEIC or the provincial inventory applied, with an exception for the April simulation with MEIC applied. The result thus implied the updated anthropogenic NMVOC emission inventory at provincial scale was still likely an underestimation of the actual emissions, as YRD was commonly recognized as a VOC-limited region for $\mathrm{O}_{3}$ formation (Xing et al., 2011). Compared to MEIC, better model performance (except for July) was generally achieved when the provincial inventory was applied, indicating the improved reliability of the de-
Table 6. Model performance of daily $1 \mathrm{~h}$ maximum $\mathrm{O}_{3}$ concentrations using MEIC and the provincial inventory for January, April, July and October 2012 in Nanjing.

\begin{tabular}{llr|rr}
\hline & \multicolumn{2}{c|}{$\begin{array}{c}\text { Provincial emission } \\
\text { inventory }\end{array}$} & \multicolumn{2}{c}{ MEIC } \\
\cline { 2 - 5 } & \multicolumn{1}{c}{ NMB* $^{*}$} & NME* $^{*}$ & NMB & NME \\
\hline January & $-21 \%$ & $34 \%$ & $-58 \%$ & $59 \%$ \\
April & $-26 \%$ & $38 \%$ & $35 \%$ & $55 \%$ \\
July & $-28 \%$ & $33 \%$ & $-23 \%$ & $29 \%$ \\
October & $-20 \%$ & $26 \%$ & $-50 \%$ & $50 \%$ \\
\hline
\end{tabular}

* Normalized mean bias (NMB) and error (NME) were calculated as the following equations $\left(P_{i}\right.$ and $O_{i}$ indicate the results from modeling prediction and observation, respectively):

$\mathrm{NMB}=\frac{\sum_{i=1}^{n}\left(P_{i}-O_{i}\right)}{\sum_{i=1}^{n} o_{i}} \times 100 \% ; \mathrm{NME}=\frac{\sum_{i=1}^{n}\left|P_{i}-O_{i}\right|}{\sum_{i=1}^{n} o_{i}} \times 100 \%$.

tailed bottom-up NMVOC inventory on the high-resolution chemistry transport simulation. In particular, larger emissions were estimated for certain species with relatively high ozone formation potential (e.g., ethene and ethanol) in the provincial inventory. It should be noted that the improved ozone simulation was a combined effect of the updated inventory with revisions on emission estimation, spatial distribution and source profiles for all the relevant species, and that the impacts of emission changes for individual species could not be completely validated. More chemistry transport mod- 


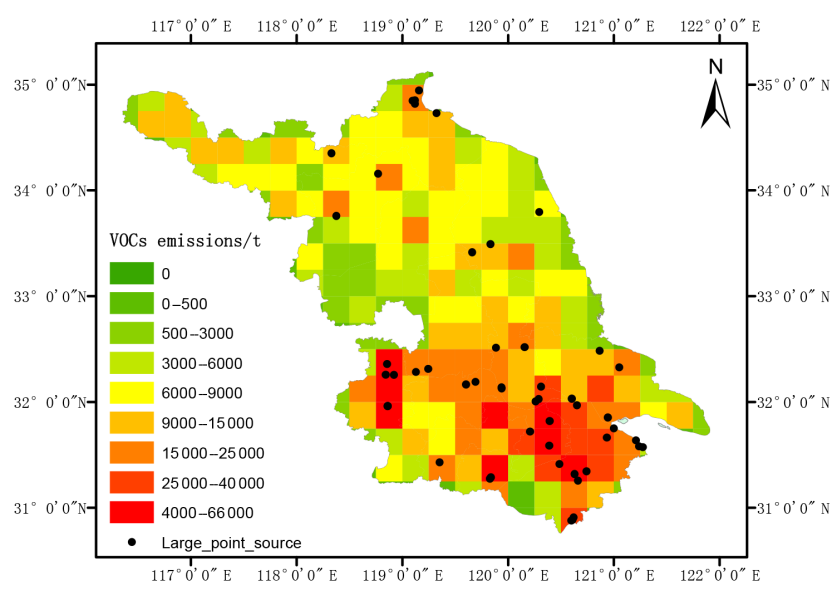

(a)

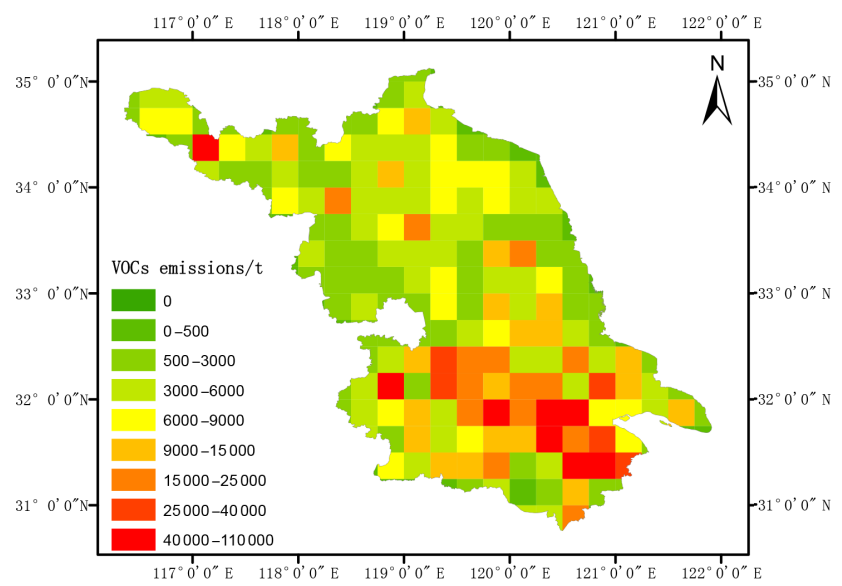

(b)

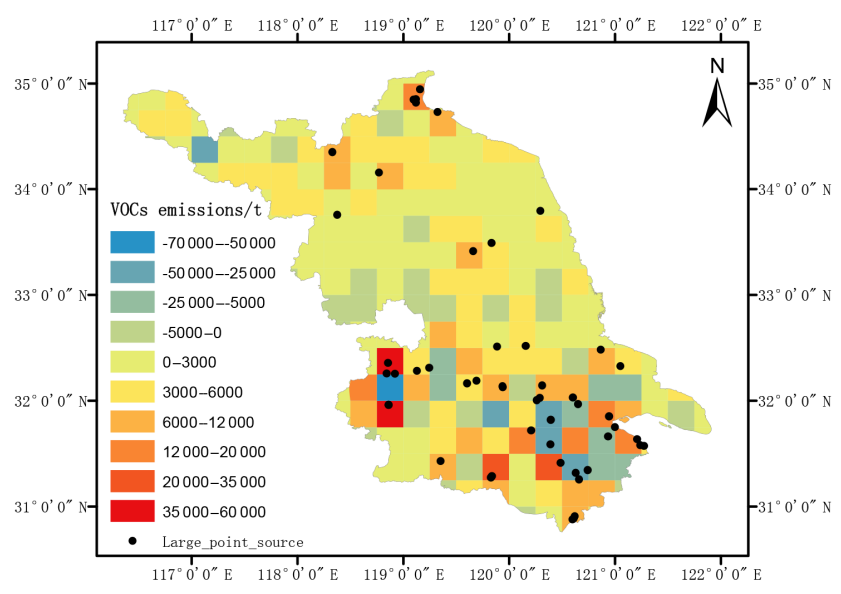

(c)

Figure 9. Spatial distributions of Jiangsu's anthropogenic NMVOC emissions for $2010\left(0.25^{\circ} \times 0.25^{\circ}\right)$ by this study (a) and MEIC (b), and the differences between the two inventories (this study minus MEIC, c). The black dots indicate the largest 50 emitters in the province.

eling is further encouraged with intensive sensitivity analysis.

The discrepancies between simulations and observations were still large compared to regional studies in North America (Y. Zhang et al., 2009). More efforts in improving or validating emission inventory at provincial scale are thus greatly needed. Besides careful compilation of emission source information in the bottom-up method, observation constraint from ground measurements could be used to evaluate the emission level, source contribution and speciation of VOC emissions (M. Wang et al., 2014). Emission uncertainty of $\mathrm{NO}_{x}$ could also partly explain the discrepancies, as the $\mathrm{NO}_{x}$ control measures taken recently could hardly be fully tracked in the emission inventory development. Besides the limitation of emission input, more analysis on the impacts of chemical mechanisms and dynamics in the chemistry transport modeling are also suggested for $\mathrm{O}_{3}$ prediction in the region.

\section{Conclusion}

Using a bottom-up approach, we developed a high-resolution emission inventory of anthropogenic NMVOCs for the Jiangsu province, eastern China, with substantial detailed information on local sources and source profiles from domestic tests incorporated. Attributed largely to the elevated contribution from industrial processes and solvent use, the annual provincial emissions were estimated to increase $41 \%$ from 2005 to 2014 . Influenced largely by the locations of big point sources, high emission densities were found in cities along the Yangtze River. Our estimations were larger than results from most other available inventories except REAS, due mainly to the omissions of certain industrial and solventuse sources by other studies and to the elevated activity levels from plant-by-plant investigation in this work. Benefiting from more detailed classification and investigation of emission sources, reduced uncertainties in annual emissions were 


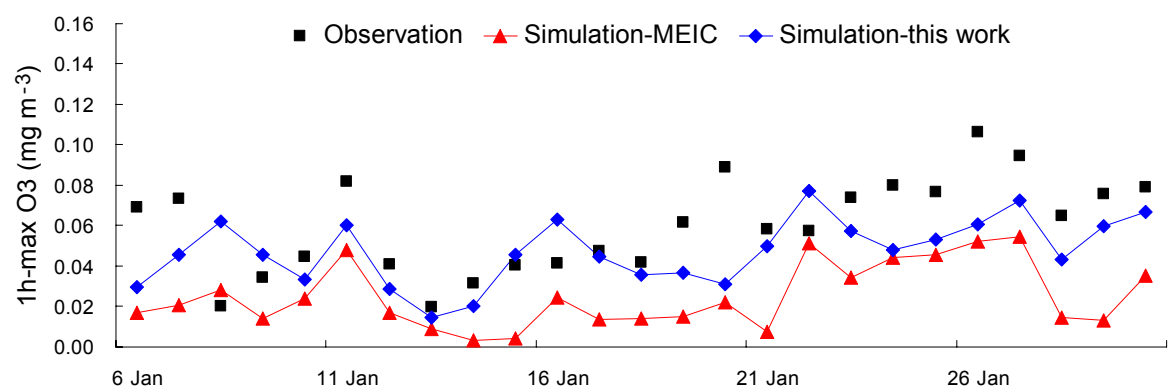

(a)

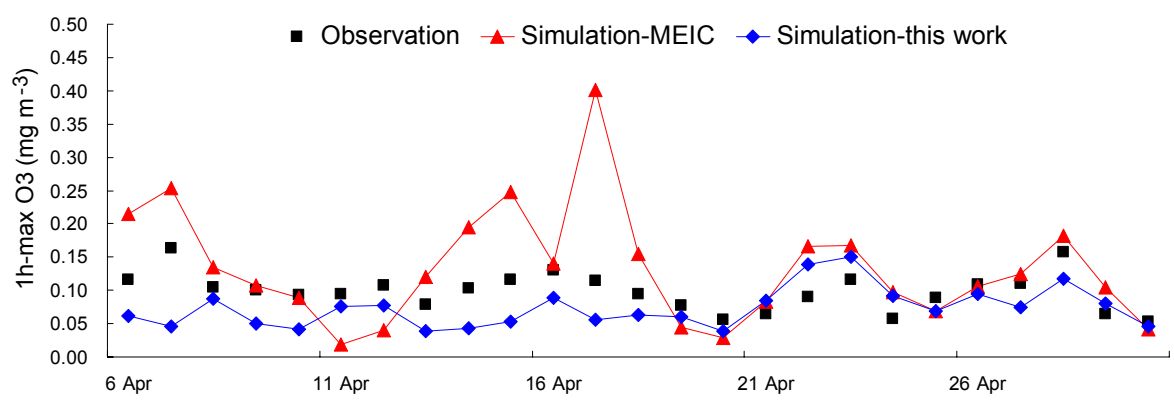

(b)

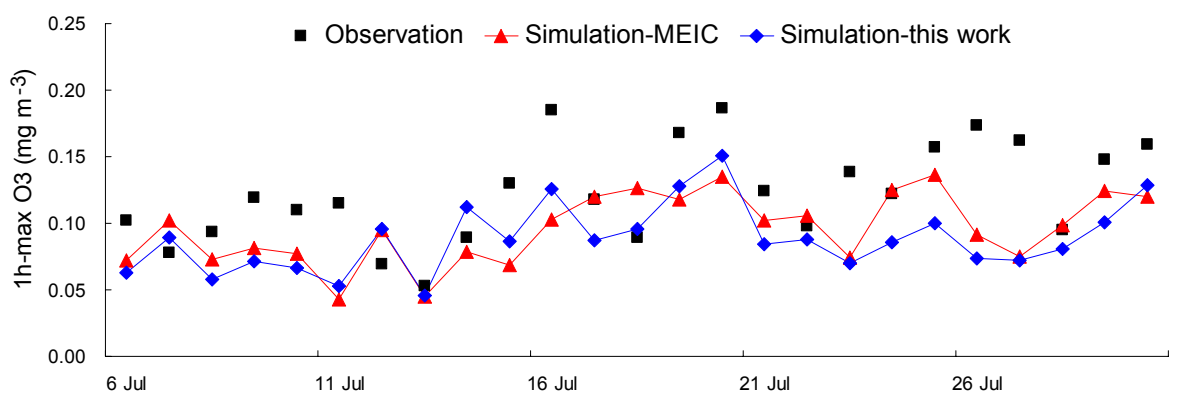

(c)

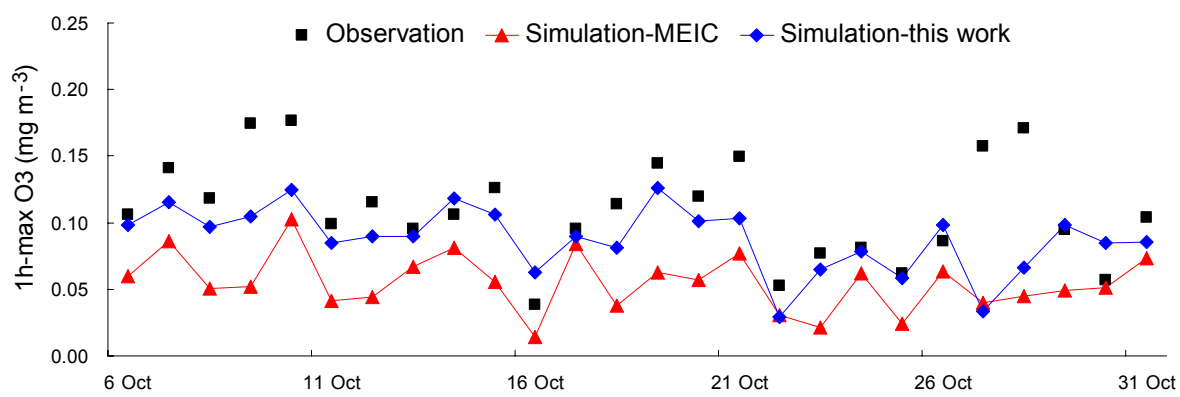

(d)

Figure 10. Observed and simulated daily $1 \mathrm{~h}$ maximum $\mathrm{O}_{3}$ concentrations using MEIC and the provincial emission inventory in January (a), April (b), July (c) and October (d) in 2012 at the air quality monitoring sites in Nanjing. Note the different $y$-axis scales between panels.

quantified in this work compared to previous studies. Varied data sources and methods had a significant impacts on emission estimation at city/plant level. In particular, downscaling directly from national inventories would overestimate the fraction of emissions in urban downtown. With the most recent source profiles from local measurements included, considerable changes in emissions were found for ethylacetate and certain aromatic species, and the speciation under CB05 and SAPRC99 differed a lot from the national MEIC inventory. Compared to MEIC, better model perfor- 
mance (indicated by daily $1 \mathrm{~h}$ maximum $\mathrm{O}_{3}$ concentrations) was achieved when the improved provincial inventory was used in the CMAQ simulation, although the discrepancies between simulations and observations need further investigation. As emission controls on NMVOCs started to be implemented on industrial sources in China (e.g., the application of leak detection and repair technique in chemical and refinery plants), more field tests were recommended to better track the temporal changes in emission factors and to reduce the uncertainty of emission estimation in the future.

Data availability. The detailed data from field measurements have been provided in the Supplement.

\section{The Supplement related to this article is available online at https://doi.org/10.5194/acp-17-7733-2017-supplement.}

Competing interests. The authors declare that they have no conflict of interest.

Acknowledgements. This work was sponsored by the Natural Science Foundation of China (91644220), the National Key Research and Development Program of China (2017YFC0210106 and 2016YFC0201507), the Natural Science Foundation of China (41575142), the Natural Science Foundation of Jiangsu (BK20140020), and the Jiangsu Science and Technology Support Program (SBE2014070918). We would like to acknowledge Qiang Zhang from Tsinghua University for providing the emission data (MEIC). Thanks also go to two anonymous reviewers for their very valuable comments that helped to improve this work.

Edited by: Gregory Frost

Reviewed by: two anonymous referees

\section{References}

Andersson, A., Deng, J., Du, K., Zheng, M., Yan, C., Skold, M., and Gustafsson, O.: Regionally-varying combustion sources of the January 2013 severe haze events over eastern China, Environ. Sci. Technol., 49, 2038-2043, 2015.

Bo, Y., Cai, H., and Xie, S. D.: Spatial and temporal variation of historical anthropogenic NMVOCs emission inventories in China, Atmos. Chem. Phys., 8, 7297-7316, https://doi.org/10.5194/acp8-7297-2008, 2008.

Cai, H. and Xie, S. D.: Estimation of vehicular emission inventories in China from 1980 to 2005, Atmos. Environ., 41, 8963-8979, 2007.

Carter, W. P. L.: Development of ozone reactivity scales for volatile organic compounds, J. Air Waste Manage., 44, 881-899, 1994.

China National Light Industry Council (CNLIC): China Light Industry Statistics 2005-2014, China Light Industry Press, Beijing, China, 2015.
European Environment Agency (EEA): EMEP/CORINAIR Emission Inventory Guidebook-2013, available at: http://www.eea. europa.eu//publications/emep-eea-guidebook-2013 (last access: 22 September 2016), 2013.

Fan, C. D., Wang, X. R., Wang, Y. Y., Liu, F., and Wu, C. D.: Anthropogenic total emissions and distribution of non-methane volatile organic compounds in China, Sichuan Environ., 3, 8287, 2012 (in Chinese).

Fu, X., Wang, S., Zhao, B., Xing, J., Cheng, Z., Liu, H., and Hao, J.: Emission inventory of primary pollutants and chemical speciation in 2010 for the Yangtze River Delta region, China, Atmos. Environ., 70, 39-50, 2013.

Gao, S., Jin, L. M., Shi, J. W., Han, B., Wang, X. Y., Peng, Y., Zhao, L. J., and Bai, Z. P.: VOCs emission characteristics and emission factors of light-duty gasoline vehicles with bench test, China Environ. Sci., 32, 397-405, 2012.

General Administration of Customs of China (GAC): China Customs Statistical Yearbook 2005-2014, China Customs Press, Beijing, China, 2015.

Geng, F., Tie, X., Xu, J., Zhou, G., Peng, L., Gao, W., Tang, X., and Zhao, C.: Characterizations of ozone, $\mathrm{NO}_{x}$, and VOCs measured in Shanghai, China, Atmos. Environ., 42, 6873-6883, 2008.

Guenther, A., Hewitt, C. N., Erickson, D., Fall, R., Geron, C., Graedel, T., Harley, P., Klinger, L., Lerdau, M., and Mckay, W. A.: A global model of natural volatile organic compound emissions, J. Geophys. Res., 100, 8873-8892, 1995.

He, K. B. (Ed.): Guidebook of Air Pollutant Emission Inventory Development for Chinese Cities, Beijing, China, 2015 (in Chinese).

He, Q., Wang, X., Zhao, L., Sheng, G., and Fu, J.: Preliminary study on profiles of VOCs emitted from coking, Environmental Monitoring in China, 21, 61-65, 2005 (in Chinese).

Huang, C., Chen, C. H., Li, L., Cheng, Z., Wang, H. L., Huang, H. Y., Streets, D. G., Wang, Y. J., Zhang, G. F., and Chen, Y. R.: Emission inventory of anthropogenic air pollutants and VOC species in the Yangtze River Delta region, China, Atmos. Chem. Phys., 11, 4105-4120, https://doi.org/10.5194/acp11-4105-2011, 2011.

Huang, C., Wang, H. L., Li, L., Wang, Q., Lu, Q., de Gouw, J. A., Zhou, M., Jing, S. A., Lu, J., and Chen, C. H.: VOC species and emission inventory from vehicles and their SOA formation potentials estimation in Shanghai, China, Atmos. Chem. Phys., 15, 11081-11096, https://doi.org/10.5194/acp-15-110812015, 2015.

Huang, R. J., Zhang, Y., Bozzetti, C., Ho, K. F., Cao, J. J., Han, Y., Daellenbach, K. R., Slowik, J. G., Platt, S. M., and Canonaco, F.: High secondary aerosol contribution to particulate pollution during haze events in China, Nature, 514, 218-222, 2014.

Intergovernmental Panel on Climate Change (IPCC): 2006 IPCC Guidelines for National Greenhouse Gas Inventories, IPCC National Greenhouse Gas Inventories Programme, Institute for Global Environmental Strategies, Japan, 2006.

Jia, J., Huang, C., Chen, C., Chen, M., Wang, H., Shao, M., Dong, Y., Dai, P., Xie, S., Lu, J., and Huang, H.: Emission characterization and ambient chemical reactivity of volatile organic compounds (VOCs) from coking processes, Acta Scientiae Circumstantiae, 29, 905-912, 2009 (in Chinese).

Klimont, Z., Streets, D. G., Gupta, S., Cofala, J., Lixin, F., and Ichikawa, Y.: Anthropogenic emissions of non-methane volatile 
organic compounds in China, Atmos. Environ., 36, 1309-1322, 2002.

Klinger, L. F., Li, Q. J., Guenther, A. B., Greenberg, J. P., Baker, B., and Bai, J. H.: Assessment of volatile organic compound emissions from ecosystems of China, J. Geophys. Res.-Atmos., 107, 11-16, 2002.

Kudo, S., Tanimoto, H., Inomata, S., Saito, S., Pan, X., Kanaya, Y., Taketani, F., Wang, Z., Chen, H., Dong, H., Zhang, M., and Yamaji, K.: Emissions of nonmethane volatile organic compounds from open crop residue burning in the Yangtze River Delta region, China, J. Geophys. Res.-Atmos., 119, 7684-7698, 2014.

Kurokawa, J., Ohara, T., Morikawa, T., Hanayama, S., JanssensMaenhout, G., Fukui, T., Kawashima, K., and Akimoto, H.: Emissions of air pollutants and greenhouse gases over Asian regions during 2000-2008: Regional Emission inventory in ASia (REAS) version 2, Atmos. Chem. Phys., 13, 11019-11058, https://doi.org/10.5194/acp-13-11019-2013, 2013.

Li, L.: The numerical simulation of comprehensive air pollution characteristics in a typical city-cluster, $\mathrm{PhD}$ thesis, Shanghai University, Shanghai, China, 2012.

Li, M., Zhang, Q., Streets, D. G., He, K. B., Cheng, Y. F., Emmons, L. K., Huo, H., Kang, S. C., Lu, Z., Shao, M., Su, H., Yu, X., and Zhang, Y.: Mapping Asian anthropogenic emissions of non-methane volatile organic compounds to multiple chemical mechanisms, Atmos. Chem. Phys., 14, 5617-5638, https://doi.org/10.5194/acp-14-5617-2014, 2014.

Li, X., Wang, S., Duan, L., Hao, J., Li, C., Chen, Y., and Yang, L.: Particulate and trace gas emissions from open burning of wheat straw and corn stove in China., Environ. Sci. Technol., 41, 60526058, 2007.

Liu, Y., Shao, M., Fu, L., Lu, S., Zeng, L., and Tang, D.: Source profiles of volatile organic compounds (VOCs) measured in China: Part I, Atmos. Environ., 42, 6247-6260, 2008.

MEP (Ministry of Environmental Protection of the P. R. China): Volatile organic compounds emission inventory guidebook, available at: http://www.zhb.gov.cn/gkml/hbb/bgg/201408/ t20140828_288364.htm (last access: 20 April 2016), 2014.

Muller, J. F.: Geographical distribution and seasonal variation of surface emissions and deposition velocities of atmospheric trace gases, J. Geophys. Res.-Atmos., 97, 3787-3804, 1992.

National Bureau of Statistics of China (NBS): China Energy Statistical Yearbook 2005-2014, China Statistics Press, Beijing, China, 2015a.

National Bureau of Statistics of China (NBS): China Industry Economy Statistical Yearbook 2005-2014, China Statistics Press, Beijing, China, 2015b.

National Bureau of Statistics (NBS): China Statistical Yearbook 2005-2014, China Statistics Press, Beijing, China, 2015c.

Ohara, T., Akimoto, H., Kurokawa, J., Horii, N., Yamaji, K., Yan, X., and Hayasaka, T.: An Asian emission inventory of anthropogenic emission sources for the period 1980-2020, Atmos. Chem. Phys., 7, 4419-4444, https://doi.org/10.5194/acp-7-44192007, 2007.

Ou, J. M., Feng, X. Q., Liu, Y. C., Gao, Z. J., Yang, Y., Zhang, Z., Wang, X. M., and Zheng, J. Y.: Source characteristics of VOCs emissions from vehicular exhaust in the Pearl River Delta region, J. Environ. Sci. China, 34, 826-834, 2014.

People's Government of Jiangsu Province (PGJP): Comprehensive utilization plan of crop straw in Jiangsu Province (2010-2015), available at: http://app.jsdpc.gov.cn:9000/pub/njsdpc/ (last access: 11 August 2015), 2009.

Shao, M., Zhang, Y., Zeng, L., Tang, X., Zhang, J., Zhong, L., and Wang, B.: Ground-level ozone in the Pearl River Delta and the roles of VOC and $\mathrm{NO}_{x}$ in its production, J. Environ. Manage., 90, 512-518, 2009.

Shi, J., Deng, H., Bai, Z., Kong, S., Wang, X., Hao, J., Han, X., and Ning, P.: Emission and profile characteristic of volatile organic compounds emitted from coke production, iron smelt, heating station and power plant in Liaoning Province, China, Sci. Total Environ., 515-516, 101-108, 2015.

Streets, D. G., Bond, T. C., Carmichael, G. R., Fernandes, S. D., Fu, Q., He, D., Klimont, Z., Nelson, S. M., Tsai, N. Y., Wang, M. Q., Woo, J. H., and Yarber, K. F.: An inventory of gaseous and primary aerosol emissions in Asia in the year 2000, J. Geophys. Res., 108, 8809, https://doi.org/10.1029/2002jd003093, 2003.

Sun, L., Xia, X., Wang, P., Zhang, R., Che, H., Deng, Z., Fei, Y., Ran, L., and Meng, X.: Surface and column-integrated aerosol properties of heavy haze events in January 2013 over the North China Plain, Aerosol Air Qual. Res., 15, 1514-2524, 2015.

Taiwan Environmental Protection Agency (ROC EPA): Air Pollution Control Fee Reporting for Stationary Sources in Public or Private Place: Emission Factors Announcement, Environmental Protection Administration of Taiwan, Taipei, Taiwan, 2009.

Tang, X. Y. and Chen, F.: Analysis of the causes and sources of air pollution in Beijing, technical report, Peking University, Beijing, China, 2002 (in Chinese).

Theloke, J. and Friedrich, R.: Compilation of a database on the composition of anthropogenic VOC emissions for atmospheric modeling in Europe, Atmos. Environ., 41, 4148-4160, 2007.

Tie, X. X., Li, G. H., Ying, Z. M., Guenther, A., and Madronich, S.: Biogenic emissions of isoprenoids and NO in China and comparison to anthropogenic emissions, Sci. Total Environ., 371, 238251, 2006.

Tsai, J. H., Lin, K. H., Chen, C. Y., Lai, N., Ma, S. Y., and Chiang, H. L.: Volatile organic compound constituents from an integrated iron and steel facility, J. Hazard. Mater., 157, 569-578, 2008.

Tsai, J. H., Chang, S., and Chiang, H.: Volatile organic compounds from the exhaust of light-duty diesel vehicles, Atmos. Environ., 61, 499-506, 2012.

Tsai, S. M., Zhang, J. J., Smith, K. R., Ma, Y., Rasmussen, R. A., and Khalil, M. A. K.: characterization of non-methane hydrocarbons emitted from various cook stoves used in China, Environ. Sci. Technol., 37, 2869-2877, 2003.

U.S. Environmental Protection Agency (USEPA): Compilation of Air Pollutant Emission Factors, available at: http://www.epa.gov/ ttn/chief/ap42/index.html (last access: 3 March 2016), 2002.

U.S. Environmental Protection Agency (USEPA): SPECIATE Version 4.4, available at: https://www3.epa.gov/ttnchie1/software/ speciate (last access: 12 November 2015), 2014.

Wang, H., Lou, S., Huang, C., Qiao, L., Tang, X., Chen, C., Zeng, L., Wang, Q., Zhou, M., and Lu, S.: Source profiles of volatile organic compounds from biomass Burning in Yangtze River Delta, China, Aerosol Air Qual. Res., 14, 818-828, 2014a.

Wang, H., Qiao, Y., Chen, C., Lu, J., Dai, H., Qiao, L., Lou, S., Huang, C., Li, L., Jing, S., and Wu, J.: Source profiles and chemical reactivity of volatile organic compounds from solvent use in Shanghai, China, Aerosol Air Qual. Res., 14, 301-310, 2014 b. 
Wang, J., Jin, L., Gao, J., Shi, J., Zhao, Y., Liu, S., Jin, T., Bai, Z., and $\mathrm{Wu}, \mathrm{C}$. .: Investigation of speciated VOC in gasoline vehicular exhaust under ECE and EUDC test cycles, Sci. Total Environ., 445-446, 110-116, 2013.

Wang, L. T.: Air quality modeling and control scenario analysis in Beijing area, $\mathrm{PhD}$ thesis, Tsinghua University, Beijing, China, 2006 (in Chinese).

Wang, M., Shao, M., Chen, W., Yuan, B., Lu, S., Zhang, Q., Zeng, L., and Wang, Q.: A temporally and spatially resolved validation of emission inventories by measurements of ambient volatile organic compounds in Beijing, China, Atmos. Chem. Phys., 14, 5871-5891, https://doi.org/10.5194/acp-14-5871-2014, 2014.

Wang, M., Cao, C., Li, G., and Singh, R. P.: Analysis of a severe prolonged regional haze episode in the Yangtze River Delta, China, Atmos. Environ., 102, 112-121, 2015.

Wang, Q. D., Huo, H., He, K. B., Yao, Z. L., and Zhang, Q.: Characterization of vehicle driving patterns and development of driving cycles in Chinese cities, Transportation Res. D-Tr. E., 13, 289297, 2008

Wang, S. X. and Zhang, C. Y.: Spatial and temporal distribution of air pollutant emissions from open burning of crop residues in China, Sciencepaper Online, 5, 329-333, 2008.

Wang, S., Wei, W., Du, L., Li, G., and Hao, J.: Characteristics of gaseous pollutants from biofuel-stoves in rural China, Atmos. Environ., 43, 4148-4154, 2009.

Wang, Z. H., Bai, Y. H., and Zhang, S. Y.: A biogenic volatile organic compounds emission inventory for Beijing, Atmos. Environ., 37, 3771-3782, 2003.

Wei, W.: Research and forecast on Chinese anthropogenic emissions of volatile organic compounds, $\mathrm{PhD}$ thesis, Tsinghua University, Beijing, China, 2009.

Wei, W., Wang, S., Chatani, S., Klimont, Z., Cofala, J., and Hao, J.: Emission and speciation of non-methane volatile organic compounds from anthropogenic sources in China, Atmos. Environ., 42, 4976-4988, 2008.

Wei, W., Wang, S., and Hao, J.: Uncertainty analysis of emission inventory for volatile organic compounds from anthropogenic source in China, Environm. Sci., 32, 305-312, 2011 (in Chinese).

Wei, W., Cheng, S., Li, G., Wang, G., and Wang, H.: Characteristics of volatile organic compounds (VOCs) emitted from a petroleum refinery in Beijing, China, Atmos. Environ., 89, 358-366, 2014.

Xia, S. J., Zhao, Q. Y., Li, B., and Shen, G. F.: Anthropogenic source VOCs emission inventory of Jiangsu province, Res. Environ. Sci., 27, 120-126, 2014 (in Chinese).

Xing, J., Wang, S. X., Jang, C., Zhu, Y., and Hao, J. M.: Nonlinear response of ozone to precursor emission changes in China: a modeling study using response surface methodology, Atmos. Chem. Phys., 11, 5027-5044, https://doi.org/10.5194/acp-115027-2011, 2011.

Yuan, B., Shao, M., Lu, S., and Wang, B.: Source profiles of volatile organic compounds associated with solvent use in Beijing, China, Atmos. Environ., 44, 1919-1926, 2010.

Zhang, J., Smith, K. R., Ma, Y., Ye, S., Jiang, F., Qi, W., Liu, P., Khalil, M. A. K., Rasmussen, R. A., and Thorneloe, S. A.: Greenhouse gases and other airborne pollutants from household stoves in China: a database for emission factors, Atmos. Environ., 34, 4537-4549, 2000.
Zhang, Q., Streets, D. G., Carmichael, G. R., He, K. B., Huo, H., Kannari, A., Klimont, Z., Park, I. S., Reddy, S., Fu, J. S., Chen, D., Duan, L., Lei, Y., Wang, L. T., and Yao, Z. L.: Asian emissions in 2006 for the NASA INTEX-B mission, Atmos. Chem. Phys., 9, 5131-5153, https://doi.org/10.5194/acp-9-5131-2009, 2009.

Zhang, Y., Vijayaraghavan, K., Wen, X., Snell, H. E., and Jacobson, M. Z.: Probing into regional ozone and particulate matter pollution in the United States: 1. A 1 year CMAQ simulation and evaluation using surface and satellite data, J. Geophys. Res., 114, D22304, https://doi.org/10.1029/2009JD011898, 2009.

Zhang, Y. H., Su, H., Zhong, L. J., Cheng, Y. F., Zeng, L. M., Wang, X. S., Xiang, Y. R., Wang, J. L., Gao, D. F., and Shao, M.: Regional ozone pollution and observation-based approach for analyzing ozone-precursor relationship during the PRIDEPRD2004 campaign, Atmos. Environ., 42, 6203-6218, 2008.

Zhang, Y. S., Shao, M., Lin, Y., Luan, S., Mao, N., Chen, W., and Wang, M.: Emission inventory of carbonaceous pollutants from biomass burning in the Pearl River Delta Region, China, Atmos. Environ., 76, 189-199, 2013.

Zhao, Y., Nielsen, C. P., Lei, Y., McElroy, M. B., and Hao, J.: Quantifying the uncertainties of a bottom-up emission inventory of anthropogenic atmospheric pollutants in China, Atmos. Chem. Phys., 11, 2295-2308, https://doi.org/10.5194/acp-112295-2011, 2011.

Zhao, Y., Zhang, J., and Nielsen, C. P.: The effects of recent control policies on trends in emissions of anthropogenic atmospheric pollutants and $\mathrm{CO}_{2}$ in China, Atmos. Chem. Phys., 13, 487-508, https://doi.org/10.5194/acp-13-487-2013, 2013.

Zhao, Y., Zhang, J., and Nielsen, C. P.: The effects of energy paths and emission controls and standards on future trends in China's emissions of primary air pollutants, Atmos. Chem. Phys., 14, 8849-8868, https://doi.org/10.5194/acp-14-8849-2014, 2014.

Zhao, Y., Qiu, L. P., Xu, R. Y., Xie, F. J., Zhang, Q., Yu, Y. Y., Nielsen, C. P., Qin, H. X., Wang, H. K., Wu, X. C., Li, W. Q., and Zhang, J.: Advantages of a city-scale emission inventory for urban air quality research and policy: the case of Nanjing, a typical industrial city in the Yangtze River Delta, China, Atmos. Chem. Phys., 15, 12623-12644, https://doi.org/10.5194/acp-15-126232015, 2015.

Zheng, J., Zhang, L., Che, W., Zheng, Z., and Yin, S.: A highly resolved temporal and spatial air pollutant emission inventory for the Pearl River Delta region, China and its uncertainty assessment, Atmos. Environ., 43, 5112-5122, 2009.

Zheng, J., Yu, Y., Mo, Z., Zhang, Z., Wang, X., Yin, S., Peng, K., Yang, Y., Feng, X., and Cai, H.: Industrial sector-based volatile organic compound (VOC) source profiles measured in manufacturing facilities in the Pearl River Delta, China, Sci. Total Environ., 456-457, 127-136, 2013.

Zhou, Y., Zhao, Y., Mao, P., Zhang, Q., Zhang, J., Qiu, L., and Yang, Y.: Development of a high-resolution emission inventory and its evaluation and application through air quality modeling for Jiangsu Province, China, Atmos. Chem. Phys., 17, 211-233, https://doi.org/10.5194/acp-17-211-2017, 2017. 